Illinois State University

ISU ReD: Research and eData

Theses and Dissertations

6-26-2015

\title{
Middle-School Girls' Behavioral Responses to Ostracism: How Much Does Inclusion Cost?
}

Ashley Leja

Illinois State University, amleja12@gmail.com

Follow this and additional works at: https://ir.library.illinoisstate.edu/etd

Part of the Psychology Commons

\section{Recommended Citation}

Leja, Ashley, "Middle-School Girls' Behavioral Responses to Ostracism: How Much Does Inclusion Cost?" (2015). Theses and Dissertations. 734.

https://ir.library.illinoisstate.edu/etd/734

This Dissertation is brought to you for free and open access by ISU ReD: Research and eData. It has been accepted for inclusion in Theses and Dissertations by an authorized administrator of ISU ReD: Research and eData. For more information, please contact ISUReD@ilstu.edu. 


\title{
MIDDLE-SCHOOL GIRLS' BEHAVIORAL RESPONSES TO OSTRACISM: HOW MUCH DOES INCLUSION COST?
}

\author{
Ashley M. Leja
}

132 Pages

Bullying among school-aged children is problematic in the U.S., with $22 \%$ of students aged 12-18 years reporting experiences with bullying at school (Zhang, MusuGillette, \& Oudekerk, 2016). Whereas early bullying research focused heavily on the physical bullying common among boys, more recent studies have included examinations of bullying using relational aggression. Defined as removing or threatening to remove relationships to cause harm to another, relational aggression includes behaviors such as spreading lies, gossiping, or ignoring a peer and has been found to be more common among girls (Crick \& Grotpeter, 1995; Cullerton-Sen \& Crick, 2005; Murray-Close et al., 2007). A specialized form of relational aggression that has been relatively under investigated among adolescents involves ostracism, the excluding or ignoring of others by individuals or groups (Williams, 2009).

The paucity of research on ostracism in childhood and adolescence is surprising, given that research with adults has linked ostracism to a variety of negative outcomes, including suicidal ideation or attempts, depression, and other breakdowns in psychological functioning (Saylor, Williams, Nida, McKenna, Twomey, \& Macias, 2013). Further, given the importance of healthy peer relations on child and adolescent 
psychological functioning, studying teen responses to ostracism is of great importance. Thus, the purpose of this study was to examine how adolescent girls respond to ostracism experiences in the lab. Girls' willingness to ingratiate with those who had ostracized them was of primary interest, as previous research has failed to examine teen behavior following ostracism and how it affects teens' potential for future relationships. While research with adults suggests that individuals may be prosocial to gain inclusion, it is unknown whether ostracized youth will attempt to ingratiate with ostracizers as a means to gain the inclusion that is crucial to teen development. As such, this was the first known study to examine how individual differences among middle school-aged girls' socialcognitive functioning moderated their affective and behavioral responses to being ostracized.

Fifth through $8^{\text {th }}$ grade girls $(N=110)$ completed several surveys assessing individual differences, including those related to involvement as perpetrator or victim of relational and overt aggression. At least one week after completion of these surveys, girls participated in a game of Cyberball in which they were randomly assigned to be either fully or partially ostracized. Following the game, participants completed the Primary Needs Questionnaire-Children (PNQ-C; Zadro et al., 2013) to assess need threat, as well as a resource allocation task in which they had the opportunity to "buy" inclusion in a second game of Cyberball by giving cookies to the original game players or an uninvolved player. After these tasks, participants played a final game of Cyberball in which they were fully included. Results indicated that girls who were fully ostracized in the game experienced significantly more need threat than those who were partially ostracized. In addition, girls who were partially ostracized made a greater effort to 
ingratiate with original players compared to girls who were fully ostracized. Hypotheses regarding the moderating role of relational aggression were not supported. However, a history of involvement in overt aggression did moderate resource allocation of cookies, with more frequent engagement in these behaviors associated with greater ingratiation towards original players. In addition, girls' feelings of threat to belonging following ostracism mediated the relationship between level of ostracism and their ingratiating behaviors.

Results suggest that ostracism is harmful regardless of one's history of involvement with aggression, indicating that school-based professionals working with teens have an obligation to identify and intervene when ostracism is occurring. Further, girls who were partially ostracized and believed they could gain inclusion in the second Cyberball game chose to ingratiate with ostracizing players to "buy" their inclusion. This finding suggests a need for adults to assist in teaching social skills and structuring healthy interactions so that youth are not exploited by more socially skilled peers. In addition, study results make an important theoretical contribution to the ostracism literature. Specifically, girls' threat to belonging was the process through which ostracism influenced ingratiation behaviors. This mediation was previously unstudied in teens and adds support to Williams' (2009) theory that threatened needs influence individuals' behavior following the ostracism experience.

KEYWORDS: Ostracism, Relational Aggression 
MIDDLE-SCHOOL GIRLS' BEHAVIORAL RESPONSES TO OSTRACISM: HOW MUCH DOES INCLUSION COST?

ASHLEY M. LEJA

A Dissertation Submitted in Partial Fulfillment of the Requirements for the Degree of DOCTOR OF PHILOSOPHY Department of Psychology ILLINOIS STATE UNIVERSITY 
Copyright 2017 Ashley M. Leja 
MIDDLE-SCHOOL GIRLS' BEHAVIORAL RESPONSES TO OSTRACISM: HOW MUCH DOES INCLUSION COST?

ASHLEY M. LEJA

COMMITTEE MEMBERS:

Steven E. Landau, Chair

Eric D. Wesselmann

Leandra N. Parris

Amy Hurd 


\section{ACKNOWLEDGMENTS}

First, I would like to thank Dr. Steven Landau for chairing this project. His commitment to research and student success inspires me. I greatly appreciate the time he took to push me to be my best and am a better researcher because of him. In addition, Drs. Eric Wesselmann, Leandra Parris, and Amy Hurd have been wonderful committee members, and their support throughout this process has meant the world to me. Appreciation is also due to the school staff who worked with me to recruit students and find space for me to conduct the study, as well as Kelsey Atteberry and Kristine Nichols for their help with data collection. I simply could not have done this without them.

My parents and brother have been an amazing support throughout my academic career. I will never express enough thanks to my family for giving me the opportunity to pursue this degree, the strength to keep going when it was difficult, and the sense of humor to know when not to take myself too seriously. I could go on for pages about the support of my friends, but you all know who you are and how you have touched my life. And to my best friend - thank you. It is truly difficult to find words strong enough to explain what your encouragement has meant to me. You have always understood what this journey has been like, and your love and belief in me throughout it has been unmatched.

A.M.L. 


\section{CONTENTS}

Page

ACKNOWLEDGMENTS $\quad$ i

CONTENTS

TABLES $\quad$ iv

FIGURES

CHAPTER

I. INTRODUCTION 1

II. LITERATURE REVIEW 6

$\begin{array}{ll}\text { Bullying and Victimization } & 6\end{array}$

$\begin{array}{ll}\text { Physical and Verbal Bullying } & 7\end{array}$

Relational Aggression/Bullying $\quad 8$

$\begin{array}{ll}\text { Ostracism } & 12\end{array}$

Ostracism Research with Adults $\quad 13$

$\begin{array}{ll}\text { Partial Ostracism } & 23\end{array}$

Ostracism in Childhood and Adolescence 24

Individual Difference Variables 33

History of Victimization $\quad 34$

Engagement in Aggressive Behaviors $\quad 35$

Normative Beliefs about Aggression $\quad 36$

Need to Belong $\quad 37$

$\begin{array}{ll}\text { Summary } & 38\end{array}$

Research Questions and Hypotheses 39 
Research Question 1A $\quad 40$

Research Question 1B 41

Research Question 2A 43

Research Question 2B 45

$\begin{array}{ll}\text { III. METHOD } & 49\end{array}$

Participants $\quad 49$

$\begin{array}{ll}\text { Measures } & 50\end{array}$

Individual Differences in Social-Cognitive Functioning $\quad 50$

Participants' Responses to Ostracism 56

$\begin{array}{ll}\text { Procedure } & 60\end{array}$

$\begin{array}{lll} & 63\end{array}$

Preliminary Analyses $\quad 63$

Hypothesis Testing $\quad 69$

Research Question 1A $\quad 69$

$\begin{array}{ll}\text { Research Question 1B } & 70\end{array}$

Research Question 2A $\quad 71$

Research Question 2B 73

Summary of Hypothesis Testing 75

$\begin{array}{ll}\text { Additional Findings } & 75\end{array}$

Mediation Involving Need Threat $\quad 75$

Moderation Involving Overt Victimization and Perpetration $\quad 78$

Moderation Involving Bully-Victim Status $\quad 81$

$\begin{array}{llr}\text { V. DISCUSSION } & 85\end{array}$

Preliminary Findings $\quad 90$

Major Findings $\quad 92$

Summary and Implications 101

Limitations 106

$\begin{array}{ll}\text { REFERENCES } & 109\end{array}$ 


\section{TABLES}

Table

1. Descriptive Statistics for the SEQ $(N=110)$ 52

2. Descriptive Statistics for the CSBS-S $(N=110)$

3. Descriptive Statistics for the NOBAGS $(N=110)$

4. Descriptive Statistics for the PNQ-C $(N=110)$

5. Bivariate Correlations between Predictor Variables $(N=110)$

6. Condition Predicting Cookie Distribution Individual Need Threat Analysis 77

7. Moderation of Victimization, Perpetration, and Bully-Victimization on Need Threat and Ingratiation 


\section{FIGURES}

$\begin{array}{lll}\text { Figure } & \text { Page }\end{array}$

1. Hypothesized interaction of condition by victimization history related to need threat

2. Hypothesized interaction of condition by history of perpetration related to need threat

3. Hypothesized interaction of condition by victimization history related to cookie distribution

4. Hypothesized interaction of condition by history of perpetration related to cookie distribution

5. Procedure

6. Simple slopes of level of ostracism predicting cookie distribution for $1 S D$ below the mean on overt victimization (i.e., Low $\mathrm{OV}$ ) and $1 S D$ above the mean on overt victimization (i.e., High OV)

7. Simple slopes of level of ostracism predicting cookie distribution for $1 S D$ below the mean on overt bully-victim behaviors (i.e., Low OBV) and $1 S D$ above the mean on overt bully-victim behaviors (i.e., High OBV). 


\section{CHAPTER I \\ INTRODUCTION}

Child and adolescent peer relations play an important role in the healthy social development of children and teens. Opportunities for interactions with peers begin very early in life for many children, especially those enrolled in preschool or child care settings, and these interactions continue to grow in importance throughout childhood (Parker, Rubin, Erath, Wojslawowicz, \& Buskirk, 2006). Indeed, with the exception of early infancy, friendships with peers can be found at all points during the individual's life (Bukowski, Motzoi, \& Meyer, 2009). Middle childhood into adolescence becomes an especially relevant and critical time period for the role of peer relations in social development. During this period, adolescents begin to spend more time interacting with their peers than with family members, and these interactions occur with decreasing adult guidance (Parker et al., 2006). Further, as these relationships with peers become more prominent, adolescents begin to rely more closely on their friends for social support ( $\mathrm{La}$ Greca \& Harrison, 2005).

Given the increased importance adolescent youth place on their relationships with peers, researchers have sought to examine the influence peer relations have over the course of child and adolescent development. Fortunately, research indicates that the positive peer relationships of children and teens can act as a protective factor for those at risk for adjustment problems. According to Berndt (2002), researchers have found that 
children's positive relationships with peers are associated with higher perceived social acceptance, self-esteem, and school involvement. In addition, positive peer relations in early childhood are associated with social competence and fewer instances of behavior problems than those found among children who are not viewed favorably by peers (Hay, Payne, \& Chadwick, 2004). Having close friendships with peers can also benefit children and adolescents in their broader social networks, as these positive relationships may help foster contact with other peers and promote positive social adjustment in the larger peer group (Berndt, 2004). In other words, if children and adolescents have positive relationships with their peers, they will spend more time with these peers. As a consequence, children and teens will have more opportunities to learn age-appropriate social behaviors through modeling and social reinforcement, as well as more opportunities for acceptance in the peer group.

Unfortunately, not all youth develop positive peer relationships, and multiple review papers examining research on negative peer relations clearly indicate that peer problems predict a host of negative outcomes. Reviews by Ladd (1999) and Hay et al. (2004) report that poor peer relationships and victimization are related to current and future internalizing difficulties (e.g., feelings of loneliness and depression), and recent longitudinal research verifies these findings. For example, Zwierzynska, Wolke, and Lereya (2013) found that childhood victimization predicts depressive symptoms, even after controlling for other individual differences such as gender and family adversity. Negative consequences related to poor peer relationships in childhood and adolescence 
may also extend into adulthood, with research indicating a strong association between early peer problems and future adult mental health problems (Parker et al., 2006).

Poor peer relationships have also been associated with future externalizing disorders. According to Hay and colleagues (2004), being rejected by peers may be directly related to increased involvement in antisocial activities and aggression, and lead to association with deviant peer groups. In addition, involvement with antisocial peers is related to future externalizing behavior problems, indicating that involvement with deviant peers in childhood constitutes a robust pathway to antisocial problems in adolescence (Laird, Jordan, Dodge, Pettit, \& Bates, 2001). Research has also shown that poor peer relations affect academics, as victimization has been linked to future classroom disengagement and school avoidance (Buhs, Ladd, \& Herald, 2006). In addition, Wentzel, Barry, and Caldwell (2004) found that children who did not have a reciprocated friendship in sixth grade showed lower levels of prosocial behavior and academic achievement than those who did have a reciprocated friendship. Further, students without a reciprocated friendship also reported higher level of emotional distress in both sixth and eighth grade. Thus, it is clear that difficulties in peer relations can be detrimental to children's adjustment across many domains of functioning and continued research on this topic is important. As such, one purpose of this study was to focus on the topic of children's peer relationships.

Within the context of peer relations in childhood and adolescence, bullying has received a great deal of attention in recent years. Bullying involves repeated, intentional aggressive acts perpetrated by an individual who is more physically or socially powerful 
than the victim with the intent to cause distress or harm (Olweus, 1993). Although research has traditionally focused on physical forms of bullying, early research conducted by Nicki Crick and her colleagues in the mid-1990s began to expand upon this narrow, male-dominated focus to include relational aggression and bullying, which involves the threat or removal of relationships in order to cause harm to another (Crick \& Grotpeter, 1995). Including relational forms of aggression in research on peer relations is of great importance, as the consequences for victims are just as dire as those found for children and adolescents who are victimized through physical means. For example, multiple studies have shown that relational aggression is associated with social-psychological difficulties, including internalizing and externalizing difficulties, peer rejection, and suicidal ideation and attempts (Brunstein Klomek, Marrocco, Kleinman, Schonfeld, \& Gould, 2008; Crick et al., 1997; Crick \& Grotpeter, 1995; Zwierzynska et al., 2013).

Contrary to findings involving physical aggression, a good deal of research has found that relationally aggressive behaviors are the predominant form of bullying among girls (Crick, Casas, \& Mosher, 1997; Crick \& Nelson, 2002; Cullerton-Sen \& Crick, 2005; Rose \& Rudolph, 2006). This difference may be explained by the effect of gender on children's peer relationships. For example, girls tend to spend more time in social conversation and report more self-disclosure to their friends, desire closeness within their relationships, and display more empathy than boys; boys, however, are more concerned with asserting dominance within their peer groups (Rose \& Rudolph, 2006). Thus, because girls tend to place higher value on intimate connections with friends, they are 
more vulnerable to the effects of relational aggression when their friendships have been threatened (Rose \& Asher, 2004; Rose \& Rudolph, 2006).

Girls who engage in relational aggression have a variety of tactics at their disposal, including spreading lies, gossiping, and ignoring others (Crick \& Grotpeter, 1995; Murray-Close, Ostrov, \& Crick, 2007). A specialized form of relational aggression that has been relatively under investigated among adolescents is ostracism, the excluding and ignoring of others by individuals or groups (Williams, 2009). The paucity of research on ostracism in childhood and adolescence is surprising, given that research with adults has linked ostracism to a variety of negative outcomes, including suicidal ideation or attempts, depression, and other breakdowns in psychological functioning (Saylor, Williams, Nida, McKenna, Twomey, \& Macias, 2013). Further, given the importance of healthy peer relations on child and adolescent psychological functioning, studying the teen response to ostracism is of great importance. Thus, the purpose of this study was to examine how adolescent girls responded to ostracism experiences in the lab. This was the first known study to examine how individual differences among middle school-aged girls' social-cognitive functioning moderated their responses to being ostracized. 


\section{CHAPTER II}

\section{LITERATURE REVIEW}

\section{Bullying and Victimization}

Bullying among school-aged children has received a great deal of attention from researchers and the public in recent years. Generally, bullying involves repeated, deliberately aggressive behavior towards another, characterized by an imbalance of power and systematic abuse (Olweus, 1993; Rigby, 2002). A study conducted by the National Center for Education Statistics (NCES) revealed the ongoing nature of this problem, as approximately $22 \%$ of students aged $12-18$ years reported experiencing bullying at school during the school year in 2013 (Zhang et al., 2016). Further attention has been generated by the acclaimed documentary, Bully (Waitt \& Hirsch, 2011), demonstrating the heightened concern of parents, educators, and public policy makers within the U.S. The scope of bullying research extends beyond the United States, however. Researchers have sought to understand bullying and its affects in China (Cheng et al., 2010), Israel (Wolke \& Samara, 2004), Ghana (Owusu, Hart, Oliver, \& Kang, 2011), and Chile (Fleming \& Jacobsen, 2009), among others. Additionally, studies have compared prevalence rates across various countries in attempts to understand how youth around the world are affected by bullying behaviors (Craig et al., 2009; Due et al., 2005). 


\section{Physical and Verbal Bullying}

For many years, studies of bullying focused primarily on overt, physical and verbal bullying (Crick \& Grotpeter, 1995; Crick \& Nelson, 2002; Kistner et al., 2010). These traditional forms of bullying involve behaviors such as hitting, biting, kicking, pushing, making threats, taunting, and name-calling (Ma, Stewin, \& Mah, 2001; Olweus, 1993; Rigby, 2000; Tremblay et al., 2004). Previous research indicates that males are more likely to be perpetrators and victims of physical and verbal bullying and may learn the behaviors necessary for future aggressive acts (e.g., fighting skills) from their peers (Crick \& Nelson, 2002; Kistner et al., 2010; Rose \& Rudolph, 2006). However, some research has indicated no differences in definition and involvement with bullying between males and females (Monks \& Smith, 2006; Smith, Cowie, Olafsson, \& Liefooghe, 2002).

Physical and verbal bullying have also been linked to a variety of negative consequences for both victims and perpetrators (Ma et al., 2001). For bullies, their actions may be precursors to more serious aggressive behaviors involving weapons, risks of alcohol and drug abuse, depression, and suicide attempts (Aluede, Adeleke, Omoike, \& Afen-Akpaida, 2008; Ma et al., 2001; Tremblay et al., 2004). Unfortunately, recent research has found that bullies may be rewarded for their behavior at school (e.g., through high popularity), making short-term advantages of bullying outweigh the future negative consequences (Reijntjes et al., 2013).

In his review of bullying in schools, Rigby (2007) reported a variety of dire consequences associated with victimization, including drops in self-esteem, isolation, 
absenteeism (often leading to poor academic progress), poor general health, and suicide. Further, Crick and Nelson (2002) found that physical victimization by friends was not only more common among boys than girls, but was also significantly related to anxiety, social avoidance, loneliness, and internalizing problems, among others. Thus, it is clear that bullying presents a grave threat to youths' psychological and physical well-being.

\section{Relational Aggression/Bullying}

Even though physical and verbal bullying are linked to a variety of alarming consequences and deserves researchers' attention, there is another form of bullying that is associated with the same deleterious consequences; that is, bullying through relational aggression. Defined as removing or threatening to remove relationships to cause harm to another, relational aggression includes behaviors such as spreading lies, gossiping, or ignoring a peer (Crick \& Grotpeter, 1995; Murray-Close et al., 2007). A great deal of research directed toward this form of aggression grew out of Crick and Grotpeter's (1995) efforts to demonstrate that boys and girls perpetrated aggression towards peers in different ways (i.e., boys primarily use physical aggression and girls use aggression directed at harming relationships). Indeed, using a sample of students in grades 3 through 6, their study identified boys and girls who were aggressive with almost equal frequency. Specifically, the overtly aggressive at school group was largely comprised of boys ( $15.6 \%$ versus $0.4 \%$ of girls), whereas the relationally aggressive group consisted primarily of girls (17.4\% versus $2.0 \%$ of boys).

Subsequent research supports these gender differences, as many studies across age ranges have found that girls perpetrate and are victims of relational aggression at a 
higher rate than boys (Crick et al., 1997; Crick \& Nelson, 2002; Cullerton-Sen \& Crick, 2005; Rose \& Rudolph, 2006). As with boys and physical aggression, current data confirm that girls tend to experience relational victimization, with $17.0 \%$ of girls (versus 9.6\% of boys) reporting being the subject of rumors at school in 2013 (Zhang et al., 2016). Research has also sought to determine when relationally aggressive behavior is most prevalent. In a longitudinal study of aggression during middle childhood, MurrayClose et al. (2007) found an increase in relationally aggressive behaviors from 4th to 5th grade for girls, but not for boys. Further, researchers tend to agree that relational aggression peaks in late childhood or preadolescence (Archer \& Coyne, 2005; Vitaro, Brendgen, \& Barker, 2006). Despite many studies indicating large gender differences in perpetration of relational aggression, Archer (2004) notes in his meta-analysis of sex differences in aggression that these differences can be inconsistent and may vary with the age group being examined and measurement used.

Although many studies have indicated that girls engage in relational aggression more often than boys, studies have also shown that boys do engage in (and are victimized by) this form of aggression (Rose \& Rudolph, 2006). As such, considering the consequences associated with relational aggression is just as important as those found for physical aggression. Multiple studies have shown that, similar to physical aggression, relational aggression is associated with significant social-psychological difficulties for perpetrators and victims, including peer rejection, internalizing problems, and externalizing difficulties (Bowkder \& Etkin, 2014; Crick et al., 1997; Crick \& Grotpeter, 1995; Prinstein, Boergers, \& Vernberg, 2001; Zwierzynska et al., 2013). Further, 
compared to victims of overt forms of bullying, victims of relational aggression are at an increased risk for suicidal ideation and attempts (Brunstein Klomek et al., 2008; van der Wal, de Wit, \& Hirasing, 2003).

Although boys do employ relational aggression, these behaviors may be less damaging for boys than for girls. Understanding patterns of gender differences and possible harm caused by these different forms of aggression may be aided by an examination of differences in social goals, defined by Emmons (1996) as "objectives that a person strives to attain or avoid" (p. 314) and guiding forces behind behavior in social situations. Multiples studies have found a high rate of connection-oriented goals among girls during middle childhood, versus status-oriented goals found among boys during the same developmental period (Rose \& Asher, 1999; Rose \& Asher, 2004; Rose \& Rudolph, 2006). Overall, girls appear to value closeness, friendliness, and worry about losing friendships, whereas boys tend to be more concerned with controlling social situations, promoting their own interests, and presenting themselves positively to others (Rose \& Rudolph, 2006). Thus, the harm and vulnerability caused by relational aggression may be greater for girls given their concern with maintaining relationships.

Indeed, research has shown that the consequences associated with relational aggression are more salient for girls than boys (Crick, 1995; Crick, 1996; Merrell, Buchanan, \& Tran, 2006; Paquette \& Underwood, 1999). For example, when presented with hypothetical situations depicting relational provocation (e.g., not being invited to a peer's birthday party), girls in grades three through six reported greater distress than boys (Crick, 1995). In addition, Paquette and Underwood (1999) found that girls in the 7th and 
8th grades reported more negative thoughts and feelings (i.e., feeling sadder, more surprised, and worse about themselves) following victimization and were more likely to recall specific experiences with relational aggression than boys. Considering these results in relation to girls' social goals may help describe gender differences in relational aggression, as this form of aggression may be a more effective way of harming other girls (Crick, 1995).

Relational aggression also plays an important role in predicting future social adjustment for perpetrators. Another study of children in grades 3 through 6 demonstrated that relationally aggressive behaviors (as assessed through peer and teacher nomination instruments) were uniquely predictive of future adjustment and negative changes in adjustment for girls, but not boys; that is, over the course of a school year, relationally aggressive girls became more rejected by their peers, but relationally aggressive boys did not (Crick, 1996). Prinstein et al. (2001) extended research on socialpsychological adjustment to adolescents in grades 9 through 12, finding that relational aggression and relational victimization were significantly related to girls' externalizing behavior and internalizing outcomes (i.e., depression, loneliness, and self-esteem), respectively. Further, when compared to overt victimization, girls' relational victimization explained more than twice the variability in currently experienced loneliness and self-esteem (Prinstein et al., 2001).

Relationally aggressive behaviors. As mentioned above, relationally aggressive girls have many techniques at their disposal, such as spreading rumors and gossiping, withdrawing friendships, and ignoring peers (Crick \& Grotpeter, 1995), with the purpose 
of manipulating or damaging the victim's peer relationships (Crick, 1996). When attempting to measure relational aggression, researchers typically use measures that inquire about these behaviors, whether they are using peer nomination scales, teacher or parent reports, or self-report measures (Crapanzano, Frick, \& Terranova, 2010; Crick, 1996; Crick \& Grotpeter, 1995; Kuppens, Grietens, Onghena, \& Michiels, 2009). Because these relationally aggressive behaviors are most often seen among middle school-aged girls, the first purpose of this study was to investigate relational aggression among female, middle school-aged students.

Although these behaviors are important to investigate given their ties to the harmful consequences previously described, researchers cannot stop there. A specific goal of relational aggression that may be underestimated by the public and researchers is ostracism, which some have argued may be more harmful than other forms of relational or physical aggression (Saylor et al., 2013).

\section{Ostracism}

Defined by Williams (2009) as “excluding and ignoring by individuals or groups,” (p. 276) ostracism may occur in face-to-face and $e$-based social situations. To date, most research on ostracism has been conducted with adult samples. A variety of paradigms have been used to study ostracism, including ball tossing (in which participants are excluded or included from a face-to-face or online game), "Life Alone" or "Get Acquainted" paradigms (in which participants receive bogus feedback about their future social life or desirability as a work partner, respectively), and reliving or imagining ostracism experiences, among others (see Williams, 2007). 


\section{Ostracism Research with Adults}

A great deal of research examining ostracism has been guided by Williams' (2009) need-threat temporal model that suggests three stages when one experiences ostracism: the immediate (reflexive) stage, the coping (reflective) stage, and the longterm (resignation) stage. In the reflexive stage immediately following ostracism, individuals tend to experience threats to four fundamental human needs: the needs for belonging, self-esteem, control, and meaningful existence (Williams, 2007; Williams \& Gerber, 2005; Williams \& Nida, 2011). While belonging and self-esteem are associated with relational needs and maintaining social connections, meaningful existence and control needs are associated with self-efficacy and recognition (Williams, 2007; Williams \& Nida, 2011).

Following this immediate experience of pain and need threat, ostracized individuals are able to assess and cope with their experience. Williams (2009) suggests that individuals who have been ostracized should behave in ways that fortify their threatened needs (e.g., by behaving prosocially if the need to belong has been threatened). Finally, in the third stage of the model (i.e., resignation), individuals who have been ostracized for long periods of time no longer possess the ability to fortify their needs. As such, attempts to belong turn to alienation, self-esteem turns to depression, control turns to helplessness, and meaningful existence turns to feelings of worthlessness (Williams, 2009). Because of the research conducted by Williams (and the research that grew from his development of the need-threat model), we have learned a considerable amount about adults and their ostracism experience. That being said, another purpose of 
this study was to examine ostracism as a form of relational aggression among middle school-aged females.

Affective responses to ostracism. Studies examining immediate, affective responses to ostracism indicate that the experience causes psychological distress to the recipient, an effect that is largely resistant to moderation from individual difference or situational variables (Williams, 2007). Studies demonstrating reflexive responses to ostracism are reviewed here.

Distress and need-threat. As discussed above, Williams' model of ostracism posits that the experience increases negative affect and threatens individuals' needs for belonging, self-esteem, control, and meaningful existence; indeed, researchers consistently find reduction to these needs when they are measured following ostracism (Williams, 2007; Williams, 2009). These effects are typically studied using self-report measures that ask questions pertaining to participants' mood (e.g., feelings of sadness and anger), hurt feelings, or levels of the above mentioned needs. Further, to be sure that assessments are measuring the immediate, reflexive responses an individual has to ostracism, they must be administered during or immediately following the experience (Williams, 2007).

Threats to these needs have been found across a variety of paradigms, such as face-to-face ball tossing (Williams \& Sommer, 1997), cell phone texting (Smith \& Williams, 2004), internet chat rooms (Williams et al., 2002), role-playing (Williams, Bernieri, Faulkner, Gada-Jain, \& Grahe, 2000; Zadro, Williams, \& Richardson, 2005), event-contingent diary studies (Nezlek, Wesselmann, Wheeler, \& Williams, 2012), out- 
of-the-loop paradigms (Jones, Carter-Sowell, Kelly, \& Williams, 2009) and Cyberball (Williams, Cheung, \& Choi, 2000).

Research using Cyberball. One paradigm that has been used extensively in recent laboratory studies to examine reactions to ostracism is Cyberball. Developed by Williams et al. (2000), Cyberball is an online ball-toss game in which participants believe they are playing with real people. The other players, however, are actually computer-programmed e-confederates. The game will include the participant (by tossing the ball equally between all players) or ostracize the participant (by primarily tossing between the e-confederates and ignoring the participant).

Despite the remote (i.e., online and distant from direct human contact) nature of this experience, multiple studies have shown that individuals are negatively affected by Cyberball. When first testing the effects of cyberostracism using this paradigm, Williams et al. (2000) found that ostracized participants accurately perceived their ostracism and reported a lower level of belonging, lower self-esteem, and worsened mood. In an attempt to make the ostracism experienced through Cyberball even less meaningful for participants, Zadro et al. (2004) told participants that they would be playing the game with computer-generated players or that they were playing with real people. Results indicated that, regardless of the source (i.e., from a computer or a perceived real player), individuals who experienced ostracism reported more need threat than those who were included. Zadro et al. (2004) also found that individuals reported higher need threat following ostracism even when they were told that the other players did not have a choice 
in who they threw to. Thus, it appears that even seemingly meaningless ostracism experiences are sufficient to threaten needs and depress mood.

Additional research using Cyberball has demonstrated the negative affective responses across a variety of situations. For example, Zadro, Boland, and Richardson (2006) examined the role of social anxiety as a moderator of need threat following ostracism. Results indicated that social anxiety did not moderate ostracism's impact on primary needs, as all ostracized participants experienced higher need threat than those who were included. Interestingly, research has shown that ostracism threatens needs and increases distress even when individuals are given reasons to embrace ostracism. For example, Gonsalkorale and Williams (2007) found that when individuals were ostracized by the Ku Klux Klan (KKK) during a game of Cyberball, they reported lower levels of all four needs and more negative mood than those who were included. In addition, ostracism is harmful even if being excluded is profitable. Van Beest and Williams (2006) exposed participants to a Cyberball-like game in which ball tosses were associated with financial consequences. Specifically, participants began the game with a given number of euros and were told that they had to pay 50 euro cents for every ball toss they received. Although ostracism from the game lead to more money, ostracized participants reported more need threat than included participants.

Cyberball-like research has also shown that ostracism is distressing when the object being tossed is a bomb that is about to explode and ostracism leads to safety in the game. Van Beest, Williams, and Van Dijk (2011) either included or excluded participants from a ball-toss game or a bomb-toss game (in which the player holding the bomb would 
die) to test moderation based on simulated survival threat. Whereas those who were ostracized from the ball-toss game experienced more need threat and more negative mood than those in the bomb-toss game, participants ostracized from the bomb-toss still experienced need threat and negative mood. Thus, it is apparent that immediate, affective responses to ostracism can be resistant even to the knowledge that ostracism is beneficial.

Pain. Recent research indicates that social pain (i.e., the emotional reaction to perceiving exclusion from valued others) and physical pain overlap, with common physiological mechanisms underlying responses to both (MacDonald \& Leary, 2005). Indeed, despite a lack of physical harm, ostracism proves to be a very painful experience. It appears that simply remembering an experience involving ostracism is enough to cause self-reported pain. Individuals who were asked to write about an experience with social pain reported feeling more pain than those who were asked to write about past physical pain. Those who wrote specifically about ostracism indicated high levels of experienced pain, both at the time of the event and during recall (Chen, Williams, Fitness, \& Newton, 2008; Williams, 2009). Links between relived social and physical pain were further explored by Riva, Wirth, and Williams (2011), who found that recalling either physical or social pain was associated with reports of increased negative affect and higher threat to self-esteem and control needs.

Overlap between physical and social pain, especially that experienced through ostracism, has also been examined in ways other than with self-reports of pain through the use of Cyberball. For example, Eisenberger, Lieberman, and Williams (2003) used fMRI data taken during Cyberball to detect brain activation during ostracism. Participants 
were subjected to an "unintentional" ostracism condition, by which they were told their computers were not yet hooked up; therefore, they would have to watch the other participants play the game and could not be included. After a game in which the participant was included, they were then apparently "intentionally" ostracized by the other players. Regardless of the situation (unintentional versus intentional), ostracism was associated with activation of the dorsal anterior cingulate cortex (dACC) - the region of the brain associated with physical pain (Eisenberger et al., 2003). Thus, ostracism is an experience that can cause immediate, significant pain to those who experience it, even when the experience has happened in the past.

Behavioral responses to ostracism. Also interesting to the study of ostracism is how individuals react following their affective response. Following the immediate distress and need threat caused by ostracism, individuals enter a reflective, coping stage in which they tend to assess and deal with the experience. It is during this stage that responses to ostracism may be moderated by individual differences and situational variables (Williams, 2007; Williams, 2009; Williams \& Nida, 2011). For example, although Zadro et al. (2006) determined that social anxiety did not moderate immediate need threat following ostracism during Cyberball, results did indicate that socially anxious individuals recovered from ostracism at a slower pace than individuals who do not experience anxiety. Specifically, those high in social anxiety reported greater need threat than those low in anxiety 45 minutes after the ostracism experience. Further research has found differences in behavior following ostracism based on trait self-esteem (Sommer, Williams, Ciarocco, \& Baumeister, 2001), rejection sensitivity (Ayduk, 
Gyurak, \& Luerssen, 2007), gender (Williams \& Sommer, 1997), and loneliness (Cacioppo \& Hawkley, 2005).

Research utilizing Cyberball has also found that situational factors such as group membership, causes of ostracism, and attributions appear to moderate the coping and recovery of individuals who have been ostracized. For example, in a follow-up to Gonsalkorale and Williams' (2007) study examining ostracism from a despised outgroup (i.e., the KKK), African American students who thought they were being ostracized by the KKK demonstrated easier recovery than students who thought they were being ostracized by an opposing political party (e.g., Republicans; Williams, 2009). More recent research has also examined the effects of in-group versus out-group ostracism. Further extending Gonsalkorale and Williams' research, Bernstein, Sacco, Young, Hugenberg, and Cook (2010) subjected participants to ostracism from members of their own political party or a competing political party. Unlike in previous research, however, participants were provided with fake newspaper articles designed to stress the importance of political parties. By manipulating the perceived importance of party affiliation, the researchers found that group membership moderated responses to ostracism, with those experiencing in-group ostracism reporting higher need threat.

Nezlek et al.'s (2012) diary study of real-life ostracism experiences supported the Cyberball research pertaining to group membership, finding that individuals felt higher need threat when reflecting upon ostracism perpetrated by friends or others who were close to them. This study also indicated that individuals will respond more negatively when they attribute the ostracism to themselves, when they perceive the ostracism as 
punitive, and when they feel it was oblivious (i.e., the ostracizer did not notice them).

Interestingly, ostracism guided by role norms is not as distressing as these other forms of ostracism; that is, if a social norm was associated with the ostracism (e.g., a restaurant patron ignored a waiter), the event was perceived as less upsetting (than the reverse). Taken together, these studies suggest that recovery and coping responses to ostracism can be influenced by situational variables.

Fortifying threatened control and meaningful existence needs. Williams' (2009) need threat model asserts that individuals who have experienced ostracism will behave in ways that fortify their threatened needs. Those who highly value power and control may be less concerned about inclusion and behave in ways that assert dominance and force others to notice them (Williams, 2009). In addition, when individuals think that reinclusion with an individual or group is unlikely, needs for control and meaningful existence are expected to influence behavior (Smart Richman \& Leary, 2009; Williams \& Nida, 2011). This attempt may be made through the use of aggression, which Tedeschi (2001) asserts is a behavior that can reestablish power and control. Indeed, many studies have found that individuals who have been ostracized respond aggressively or with decreases in prosocial behaviors (e.g., Chow, Tiedens, \& Govan, 2008; Twenge, Baumeister, DeWall, Ciarocco, \& Bartels, 2007; Van Beest et al., 2011; Wesselmann, Butler, Williams, \& Pickett, 2010).

Warburton, Williams, and Cairns (2006) demonstrated this effect by exposing participants to loud noise blasts after experiencing either inclusion or ostracism in a faceto-face game of ball toss. Whereas one-half of the participants were allowed to control 
the onset of the noise blasts (providing them with an experience to fortify control needs), the other half were subjected to the noise at unpredictable times. Participants who had been ostracized and were deprived control over the noise blasts behaved more aggressively towards a stranger (as measured by hot sauce allocation) than participants who were included or who were ostracized and had been allowed control over the noise (Warburton et al., 2006).

Further, aggression in response to ostracism may be exacerbated in some situations. For example, studies have shown that individuals who feel as if they are unfairly excluded or did not expect the exclusion will behave more aggressively than others (Chow et al., 2008; Wesselmann et al., 2012). As reviewed by Williams (2009), "life-alone" paradigms are especially threatening to control needs and can increase aggression. Because participants are led to believe that they will end up alone, and that they have no control over this outcome, considering ways to reestablish social connections falls out of focus. As such, the control that aggression brings becomes the main choice of behavior. Further research is needed to learn more about individuals' attempts to fortify control and meaningful existence needs, especially among children and adolescents who have been subjected to chronic, repeated ostracism. The importance of this research is underscored by current events involving school shootings in the U.S. In their case analysis of 15 shooting incidents since 1995, Leary, Kowalski, Smith, and Phillips (2003) found that chronic ostracism contributed in $87 \%$ of the cases. Given the potential real-world, deadly consequences associated with chronic ostracism, this topic should be of primary importance to researchers. 
Fortifying belonging and self-esteem. Theoretically, individuals who value group inclusion will attempt to regain that inclusion following ostracism (which, in turn, will elevate self-esteem); this attempt at reinclusion may be even more likely when individuals perceive reinclusion as possible (Williams \& Nida, 2011). Attempts at reinclusion are likely related to one's "need to belong," which is defined by Baumeister and Leary (1995) as the human need "to form and maintain at least a minimum quantity of interpersonal relationships" (p. 499).

Indeed, despite the evidence that individuals may behave aggressively following ostracism, multiple studies have also found that individuals who are ostracized will behave in ways to gain reinclusion in a group. Attempts to be reincluded have taken on many forms, including increased compliance with requests (Carter-Sowell, Chen, \& Williams, 2008), nonconscious mimicry of another's behavior (Lakin, Chartrand, \& Arkin, 2008), working harder on a team task (Williams \& Sommer, 1997), social attentiveness (Pickett, Gardner, \& Knowles, 2004), conformity (Williams, Cheung, \& Choi, 2000) and extraversion (Maner, DeWall, Baumeister, \& Schaller, 2007).

In addition, Smart Richman and Leary (2009) assert that when regaining inclusion in a relationship is likely, individuals should not only try to repair the relationship, but also behave prosocially as to not damage their social standing further. Thus, it is likely that attempts at reinclusion may largely be guided by expectations for future social interactions with that group. Along this line of thinking, Maner et al. (2007) examined whether prosocial responses following rejection by a peer occurred only when participants expected a future interaction. As expected, the researchers found that rejected 
participants gave more rewards to a new interaction partner (who had not rejected them), but only when they expected a future interaction with the partner. Thus, another purpose of this study was to determine if middle school-aged girls would engage in ingratiating behaviors following ostracism experienced through Cyberball. Unlike previous studies, however, this study examined prosocial behavior when participants were given the opportunity to play another game with those who excluded them.

\section{Partial ostracism}

One way in which researchers may simulate the possibility of future inclusion is through partial ostracism. Although full ostracism does not allow for open interpretation of the situation (i.e., individuals know they are being excluded), partial ostracism is more ambiguous. Williams et al. (2000) established partial ostracism as a viable experimental condition, finding that participants who were partially ostracized in a game of Cyberball perceived receiving fewer tosses than participants in the inclusion condition. In addition, participants who were subjected to partial ostracism chose to remain in the game longer than those who were fully ostracized. Despite choosing to stay in the game longer, however, participants exposed to partial ostracism still experienced threatened belonging and self-esteem needs (Williams et al., 2000).

According to Williams (2007), implementing ostracism less strongly, as with a partial ostracism condition, may be helpful in uncovering moderators of ostracism effects. Boyes and French (2009) employed partial ostracism as an ambiguous condition during a game of Cyberball in their study examining the relationship between neuroticism and coping. Results indicated that participants in the partial ostracism 
condition who were high in neuroticism perceived themselves as having less control during the game than others. As such, these results indicated that employing partial ostracism as an ambiguous ostracism experience is promising for future research examining individual differences in responses to ostracism.

In another study utilizing two dimensions of partial ostracism, Banki (2012) varied the number of people who were ostracizing the participant or the rate of activities from which the participant was ostracized. Within a four-person Cyberball game, participants were able to identify how many of the players ostracized them and reported that they liked the group member who included them most. Further, when given the opportunity to offer group members a monetary reward, partially ostracized individuals chose to allocate more money to the player who did not ostracize them (Banki, 2012). Whereas these studies provide initial evidence for the utility of partial ostracism as a research condition for determining the differential effects of various levels of ostracism, more research needs to be done to further explain individual differences in responses to different levels of ostracism. Thus, another purpose of this study was to shed light on girls' responses to partial ostracism, including how they allocated resources to those involved in partially excluding them.

\section{Ostracism in Childhood and Adolescence}

Unfortunately, much less is known about how children and adolescents experience ostracism. Although experiences with peer rejection and victimization occur throughout childhood (Hawker \& Boulton, 2001), few research studies have focused specifically on ostracism per se. Studying the impact of ostracism among children and 
teens may be especially important given evidence that social interactions with peers provide "social practice" needed for developing and maintaining social relationships (Juvonen \& Gross, 2005). These opportunities for practice may occur at a young age, and research has shown that ostracism can occur even in preschool settings (Crick, Casas, \& $\mathrm{Ku}, 1999)$. Recent research also suggests that brain regions implicated in social cognition are still developing during adolescence. Sebastian, Viding, Williams and Blakemore (2010) argue that continued development of the "social brain," the network of brain regions involved in social cognition, during adolescence affects vulnerability to peer influence and sensitivity to peer rejection. As such, research that focuses on children's and adolescents' experiences with ostracism is an important area of study.

Consequences associated with ostracism. As discussed previously, peer victimization experiences are associated with a variety of negative outcomes. However, the consequences associated with peer exclusion specifically appear to be distinct from other types of victimization. For example, in a longitudinal study of children ages 5 through 11, Buhs et al. (2006) determined that classroom academic engagement behaviors varied based on the form of maltreatment students experienced. Children who were excluded were more likely to become disengaged from classroom activities. Further, results showed that exclusion mediated the link between peer rejection in kindergarten and poor academic achievement during middle school by influencing children's school engagement.

Recent research has shown that ostracism also has negative effects on children's cognitive processes. Hawes and colleagues (2012) exposed children (ages 8 through 12) 
to either an inclusion or ostracism condition in Cyberball before asking them to complete measures of cognitive abilities. Interestingly, gender moderated the effects of ostracism, with only girls demonstrating poorer cognitive performance than those who were included in the game. This finding is surprising given the absence of moderation by gender in adult studies. Hawes et al. (2012) note, however, that this difference may be due in part to gender differences in relational aggression and exclusion that have been reported in developmental literature. Given the apparent cognitive and academic consequences associated with ostracism, research further examining the effects of this experience on children is warranted and necessary.

Affective responses to ostracism. Research examining ostracism in childhood and adolescence has largely focused on comparisons with adults. Thus far, research suggests that, as with adults, children and adolescents experience immediate threats to belonging, self-esteem, control, and meaningful existence needs when ostracized (Abrams, Weick, Thomas, Colbe, \& Franklin, 2011; Hawes et al., 2012; Pharo, Gross, Richardson, \& Hayne, 2011; Ruggieri, Bendixen, Gabriel, \& Alsaker, 2013b). In addition, researchers have verified these results in a non-English speaking population (Ruggieri, Bendixen, Gabriel, \& Alsaker, 2013a). Despite the evidence that threats to these needs resist moderation in adult samples (Williams, 2009), research has examined potential moderators in the ways in which children and adolescents experience exclusion.

Moderating variables. Multiple studies have examined moderation of need threat following ostracism based on age (Abrams et al., 2011; Gross, 2009; Pharo et al., 2011; Sebastian et al., 2010). Together, these studies suggest that younger individuals may be 
more affected by ostracism than those who are older. For example, Abrams et al. (2011) examined the effects of ostracism experienced through Cyberball in a sample of children (ages 8 to 9 years), adolescents (ages 13 to 14 years), and adults (undergraduate students). Results indicated that all participants reported higher need threat following ostracism than inclusion. The manner in which needs were threatened, however, varied by age. Although control was threatened to a similar degree across the three age groups, children experienced significantly higher threat to self-esteem than adolescents, but lower threat to belonging than adolescents or adults. For adolescents, belonging appeared to be particularly affected when compared to other needs. In addition, threat to all four needs significantly predicted more negative mood for children.

According to Abrams et al. (2011), these results suggest differences in social context among these three groups; specifically, adolescents and adults may have more buffers against ostracism than children, but adolescents may place high value on inclusion in peer networks. Pharo et al. (2011) found similar results in their study using Cyberball. When examining differences in need threat between groups of adolescents (ages 13 to 17 years), emerging adults (ages 18 to 22 years), and young adults (ages 23 to 27 years), these researchers determined that adolescents and emerging adults experienced greater need threat than young adults. Given the age effects found in these studies, as well as the apparent impact of ostracism on mood, self-esteem, and sense of belonging in younger samples, research on ostracism in this population continues to be important.

Individual difference factors beyond age also have been studied when examining the effects of ostracism on mood and need threat in children and adolescents. For 
example, Hawes et al. (2013) examined the association between internalizing problems and need threat in a sample of children (ages 7 through 12) using Cyberball as a manipulation of ostracism. As would be expected, children who were ostracized reported greater need threat than those who were included in the game. Interestingly, though, were the findings for children who reported high levels of internalizing problems. Overall, children who reported higher levels of internalizing problems also reported greater need threat (except for control). In addition, children who had higher levels of internalizing problems and were ostracized did not report levels of need threat that differed significantly from children with low levels of internalizing problems. Although the presence of internalizing problems did not exacerbate ostracism's impact, these results are still important to ostracism research. Specifically, these results suggest that ostracism elicits cognitions that are consistent with internalizing problems even among children who are not experiencing these problems. Thus, children's exposure to ostracism may be a risk factor for future internalizing disorders, such as depression (Hawes et al., 2013).

Disability status appears to be an important moderator of the presence of ostracism experiences in childhood and adolescence; unfortunately, little research has been conducted in this area. The need is great, however, as children with physical disabilities, behavioral or emotional problems, and developmental and learning disabilities may be at increased risk for victimization through bullying (Twyman et al., 2010). In their review of literature focusing on ostracism in childhood, Saylor et al. (2013) reported that children and adolescents with developmental disabilities or diagnosed emotional/behavioral disorders were more likely to be victimized by their 
peers than youth with chronic medical conditions. When compared to youth without special health care needs, children with Autism Spectrum Disorders (ASD) and Attention-deficit/Hyperactivity Disorder (ADHD) are three to four times more likely to report victimization (Twyman et al., 2010).

Recent research also suggests that experiential factors may affect how children and adolescents respond to exclusion experiences. Ruggieri et al. (2013b) sought to expand upon past research in this domain by examining the potentially moderating role of previous victimization history. Specifically, these researchers sought to determine if victims of bullying would respond more negatively (as compared to non-victims) to ostracism induced by Cyberball. Of the children and adolescents (ages 9 through 14) who participated, approximately one-half were classified as passive victims of bullying. This classification was made based on participants' self-reported experiences with being bullied at least once per week over the previous three months (without having behaved aggressively towards peers within the same time period). Ruggieri et al. (2013b) reported that victims' moods at both pretest and posttest were significantly more negative than the moods of children who had not been involved in bullying. Further, children who were victims and had been ostracized in this study reported feelings of less belonging and less meaningful existence than those who did not have a history of victimization. For reports of meaningful existence, children who were victims scored significantly lower than those who were not victims in the ostracism condition, but not in the inclusion condition. These results suggest that children who have been victimized may have a more difficult time recovering from ostracism, making them especially important to identify for intervention. 
Results from the above described studies suggest that multiple factors affect childhood and adolescent responses to ostracism, including age, history of peer victimization, and disability status. Given the relative lack of moderation found in adult studies of affective responses to ostracism (Williams, 2009), further research on child and adolescent ostracism is warranted to help determine for whom intervention is appropriate and necessary. Thus, another purpose of this study was to further investigate potential moderators of children's affective responses to ostracism, with specific focus on victimization history.

Behavioral responses to ostracism. Similar to adult research, studies examining children's and adolescents' overt behavioral responses to ostracism will provide further insight into the various effects of exclusion. As previously discussed, Williams' (2007; 2009) model of ostracism suggests that behaviors which occur during the reflective, coping stage are more likely to be moderated by individual differences and situational variables, as well as driven by individuals' attempts to fortify threatened needs. Although less research in this area has been conducted with children and adolescents, current research shows that this segment of the population may also behave either aggressively or prosocially following incidents of exclusion.

Antisocial behaviors. Research has found that, like adults, children and adolescents may behave antisocially or aggressively following ostracism. For example, Coyne, Gundersen, Nelson, and Stockdale (2011) included or ostracized adolescents (ages 16 and 17 years) during a game of Cyberball before having them engage in a competitive reaction time test. Participants were required to choose a monetary reward 
(from $\$ 0$ to $\$ 0.50$ ) for their opponent to receive if they were to win the trial. An analysis of the amount of times participants chose to give their opponent the most generous reward (e.g., $\$ 0.45$ or $\$ 0.50$ ) indicated that adolescents who had been ostracized during their Cyberball game were less generous than those who had not been ostracized; that is, ostracized adolescents were less prosocial than adolescents who had been previously included. Coyne et al. (2011) suggested that adolescents may have experienced a "cognitive and emotional 'numbness"” (p. 660) that affects behavior following ostracism. Taking the perspective of William's (2007) need threat model, however, it is possible that the adolescents who were ostracized in Coyne et al. (2011) felt as if they needed to fortify control and meaningful existence needs rather than belonging and self-esteem needs.

Other studies have found that children and adolescents may behave aggressively following exclusion. Wölfer and Scheithauer (2013) allowed children and adolescents the opportunity to aggress against other Cyberball players during a modified version of the game. The ostracized participant was provided with two additional functions in the game: the option to throw the ball very hard to the other players (simulating aggression, an antisocial action), and the option to throw the ball to a wall and have it bounce back (simulating an avoidant reaction); or, participants could continue to play in a normal manner (simulating social reintegration, a prosocial reaction). Results indicated that participants reacted in different ways, with $55 \%$ reacting prosocially, $34 \%$ reacting in an avoidant manner, and $11 \%$ reaction antisocially. Although specific moderating effects based on questionnaire responses lacked sufficient power, those who were antisocial displayed a lower level of anger regulation, lower perspective-taking skills, and a higher 
need to belong. Although aggressive responses following ostracism for individuals with a high need to belong is contradictory to Williams' (2009) model, it appears that lower anger regulation and perspective-taking are more powerful influences in behavioral reactions. These findings are helpful in understanding which children may react aggressively following ostracism.

Prosocial behaviors. Previous research with adults has shown that one way in which individuals affiliate and try to gain reinclusion with groups is through mimicry (Lakin et al., 2008). In an attempt to determine sensitivity to ostracism in young children, Over and Carpenter (2009) examined imitation in children between ages 5 and 6 years after they had been primed for ostracism using videos in which a shape appeared to be excluded by other shapes. Compared to children who had not been primed, those who viewed the shapes excluding another shape more closely imitated an adult model's actions with a toy; this imitation suggests that children who observed the ostracism prime were more attentive to the model's demonstration.

Similar observations of attentiveness following ostracism were noted in a study of 4th and 8th graders conducted by Wölfer and Scheithauer (2013). Specifically, results showed that, when asked to remember events from diary passages of an individual whom they did not know, children and adolescents who were ostracized in Cyberball recalled more social events than those who were included in the game. According to the researchers, recalling these social events may be a way to combat negative mood and threat to belonging. Taken together, these studies suggest that children and adolescents 
may respond prosocially following ostracism as a means to fortify belonging needs and buffer against negative mood.

The current research on children's and adolescents' behavioral responses to ostracism is limited. As such, another purpose of this study was to determine additional factors that moderated children's behavioral responses to ostracism. Specifically, this study examined the moderating effect of individual difference variables on children's ingratiating behaviors following ostracism. In addition, this was the first known study to examine children's ingratiating behaviors when they expected a second interaction with the individuals who excluded them.

\section{Individual Difference Variables}

As is evident through the research described above, not all individuals employ the same behavioral strategies when responding to ostracism, and this may be largely influenced by experienced need threat. Beyond need threat, there are other individual differences that influence one's behavioral responses to ostracism. As described above, person-centered variables such as gender (Williams \& Sommer, 1997) and trait selfesteem (Ayduk et al., 2007), among others, have been shown to moderate behavioral responses to ostracism in adult populations. Thus far, much less research has been conducted on specific variables that moderate children's and adolescent's (especially girls') behavioral responses to ostracism. Because ostracism is a facet of relational aggression, variables conceptually related to this form of aggression that may impact responses to exclusion include history of victimization, current engagement in aggressive behaviors, and normative beliefs about aggression. 


\section{History of Victimization}

Intuitively, one's experience as a victim of relational or physical aggression may play a role in how one responds to ostracism. Ruggieri and colleagues (2013b) found that victimized children and adolescents experienced greater need threat and increased negative affect following ostracism through Cyberball. Research has not yet examined the role that victimization history plays in behavioral responses to ostracism, however. Although this variable has not been observed directly in recent research, studies examining correlations between victimization status and behavioral response may shed light on this issue.

For example, in their study on the developmental trajectories of victimized adolescents (ages 13 through 16), Barker, Arseneault, Brendgen, Fontaine, and Maughan (2008) determined that those who were high in victimization history were likely to belong to a high bullying trajectory group. Thus, adolescents who have been victimized have a high probability of bullying others. Additional research has found a similar pattern among younger children, whereby relational victimization in third grade was a significant predictor of perpetration of relational aggression in sixth grade (Ostrov \& Godleski, 2013). As such, there is evidence to suggest that being a victim of relational aggression and bullying may lead to future engagement in these behaviors. Thus, an important purpose of this study was to examine the impact of victimization status on girls' behavioral responses to ostracism, with a focus on whether girls who had been victimized would be less ingratiating toward those who excluded them from a game than girls with no history of victimization. 


\section{Engagement in Aggressive Behaviors}

Smart Richman and Leary (2009) report that individuals may respond aggressively following rejection for a variety of reasons, including feelings of frustration, depletion of self-esteem, loss of control, or simply to punish their rejecters, among others. Although there is extensive evidence indicating that individuals respond aggressively following rejection and ostracism, research has not examined how aggressive these individuals describe themselves before they are exposed to ostracism. It seems likely, however, that how often individuals currently engage in aggressive behaviors would impact their behavioral responses to ostracism.

Recent research has found that most children who are identified as bullies are perpetrators of both proactive and reactive aggression (Camodeca, Goossens, Terwogt, \& Schuengel, 2002; Salmivalli \& Nieminen, 2002), which Dodge and Coie (1987) have characterized as goal-directed and deliberate versus a response to provocation or anger. Thus, it seems possible that children who are aggressive (i.e., act as bullies) may respond as such when excluded by peers. Other research has shown, however, that this may not necessarily be the case. Interestingly, a recent meta-analytic study of direct and indirect aggression in childhood and adolescence conducted by Card, Stucky, Sawalani, and Little (2008) found that perpetration of indirect aggression (defined by the authors as rejection or exclusion of a victim) was associated with higher prosocial behavior. That is, relationally aggressive children must be able to use their prosocial skills as a means to gain support from peers for their actions. To date, studies have not directly examined children's aggressive tendencies in the context of their ostracism experiences. Thus, 
another purpose of this study was to examine the moderating effect of girls' history of being aggressive on their ingratiating behaviors following their ostracism experience. It was anticipated that girls who reported high engagement in aggressive behaviors (including verbally, physically, and relationally aggressive behaviors) would engage in a lower level of ingratiating behaviors towards others who ostracized them.

\section{Normative Beliefs about Aggression}

According to Huesmann and Guerra (1997), an individual's normative beliefs about aggression refers to one's level of acceptance of aggression as a solution to social challenges. As such, these beliefs guide one's actions by determining which behaviors are tolerable and which are not in conflict situations. Research has found that children and adolescents who believe that aggression is normative are more likely to engage in aggressive behaviors (Huesmann \& Guerra, 1997; Salmivalli \& Voeten, 2004; Werner \& Hill, 2010). Further, normative beliefs about aggression may influence responses to aggression in others. For example, Howard, Landau, and Pryor (2014) found that boys who were more tolerant of aggression and viewed another player being bullied before a Cyberball game were more likely to exclude the victim when a bystander joined in or did nothing about the bullying than boys who were not tolerant of aggression.

Whereas Huesmann and Guerra's (1997) initial examination of normative beliefs about aggression focused on overt, physical aggression, other researchers have studied these beliefs in the context of relational aggression. For example, Crick, Bigbee, and Howes (2006) examined whether children believe that relationally aggressive behaviors are "aggressive" and if they are normative responses when angry. Results indicated that 
both boys and girls associated behaviors consistent with relational aggression (e.g., telling lies about a friend who has made them angry) with anger. In addition, children viewed relationally aggressive behaviors as more normative for girls than boys. The difference was most pronounced among fifth and sixth graders.

Murray-Close, Crick, and Galotti (2006) also compared children's beliefs regarding physical and relational aggression. As would be expected from past research, children's ratings regarding the "wrongness" of physical and relational aggression were related to peer and teacher reports of aggressive behaviors, with the children rating aggression as wrong being less likely to engage in aggressive behaviors. Findings also indicated that ratings of the harmfulness of physical aggression were equal among girls and boys, but that girls were more likely than boys to believe that relational aggression was harmful. Thus, girls seem to show particular sensitivity to relational aggression (Murray-Close et al., 2006). Given children's views concerning relational aggression as harmful and the association between beliefs about aggression and engagement in aggressive behaviors, it seems likely that these beliefs could influence responses to ostracism. In this study, normative beliefs about aggression were used to provide additional descriptive information about study participants. Specifically, as found in previous research, it was anticipated that children who reported higher engagement in aggressive behaviors would also report more tolerance for aggression.

\section{Need to Belong}

While studied among children than adults, need to belong as defined by Baumeister and Leary (1995) may also play a role in teen behavior following ostracism. 
Although not specific to the exclusion experience, Olthof and Goossens (2008) examined need to belong as a motive in children's bullying-related behavior. Specifically, children aged 10 to 13 years were asked to rate items assessing their desire to be accepted by their classmates and engaged in peer nomination procedures to determine involvement in bullying. Results indicated that children's desire to be accepted by their peers was a motive for participation in bullying behaviors such that boys', but not girls', bullying behavior was related to their need to be accepted by same-sex peers who engaged in bullying. However, girls' bullying behaviors were related to their desire to be accepted by boys. Thus, it appears that children's engagement in bullying-related behaviors may be tied to their need to belong with others who engage in those behaviors.

As previously discussed, striving for reinclusion following ostracism has been found in a variety of studies involving adults. Some recent studies have also expanded this research to include child responses after the ostracism experience, finding that children may behave antisocially (as found by Coyne et al., 2011) or prosocially through affiliative attempts (as shown by Lakin et al., 2008). Given the relative lack of research on youth responses following ostracism and the role that a need to belong plays in responses to ostracism, participants' need to belong was examined as a potential moderator in this study, as well as a measure of additional demographic information about participants.

\section{Summary}

As described above, individual differences such as history of victimization and current engagement in relationally aggressive behaviors may predict children's behaviors, 
and may influence how children respond following exposure to ostracism. Given these relations, this study examined how these individual differences moderated girls' affective and behavioral responses following exposure to partial and full ostracism, with a specific focus on their engagement in ingratiating behaviors towards the e-players who left them out of the game.

\section{Research Questions and Hypotheses}

Participants completed a series of self-report questionnaires to assess their individual differences before participating in a game of Cyberball in which they were either partially or fully ostracized. Immediately following the game, affective responses (i.e., need threat) were assessed through a self-report questionnaire. In addition, participants engaged in a resource allocation activity in which they were given the opportunity to give cookies to the game players. The purpose of this resource allocation was to determine if participants would behave in an ingratiating manner towards those players who left them out of the game. This was the first known study to behaviorally assess middle school-aged girls' ingratiating responses to exclusion when they knew they would get a second opportunity to play with those who excluded them. In other words, this study sought to determine the moderating effect of individual differences on girls' willingness to ingratiate themselves to players who ostracized them.

It was anticipated that the level of exposure to ostracism (i.e., partial vs. full ostracism) would elicit differences in participants' affective and behavioral responses to ostracism. Further, it was anticipated that the participants' individual differences in relational aggression history and social-cognitive functioning would interact with 
ostracism in a differential way and reveal that ostracism affects different girls in different ways.

\section{Research Question 1A}

Does being fully versus partially ostracized have a differential effect on participants' affective responses (i.e., self-reported need threat) following the Cyberball exclusion experience?

Hypothesis 1A: Affective responses to partial versus full ostracism. For the purpose of this study (and consistent with previous research with children and adolescents), participants' affective responses following ostracism were assessed using self-reports regarding threats to belonging, self-esteem, control, and meaningful existence needs (Abrams et al., 2011; Hawes et al., 2012; Pharo et al., 2011; Ruggieri et al., 2013b). Previous research has shown that adults will experience need threat even when they are only partially ostracized (Williams et al., 2000). In a recent pilot study with children and adolescents, Leja, Wesselmann, and Landau (2014) found that middle school-aged girls who were exposed to varying levels of ostracism experienced different levels of need threat. Specifically, girls who were fully ostracized reported significantly more need threat than those who were partially ostracized. Thus, it was hypothesized in this study that participants who were fully ostracized would report greater need threat than those who were partially excluded. In other words, girls who were fully excluded from the game would experience less belonging, self-esteem, control, and meaningful existence compared to girls who were only partially excluded. 


\section{Research Question 1B:}

Do individual differences in one's history of relational aggression victimization and/or perpetration moderate the effects of ostracism on participants' resilience to ostracism as defined by need threat?

\section{Hypothesis 1B: Moderating effect of self-reported history of victimization} and/or perpetration on need threat. Participants' history of physical and relational victimization will be assessed using a self-report measure. Previous research conducted by Ruggieri et al. (2013b) indicated that children and adolescents who have experienced physical and relational aggression report greater need threat and more intense negative affect following full ostracism during the Cyberball game. As such, it was expected that participants' self-reported level of need threat would be amplified by history of victimization. Specifically, participants' reporting more frequent victimization would report higher need threat following ostracism. To date, researchers have not examined girls' affective responses following partial ostracism. Given that partial ostracism is a more ambiguous condition than full ostracism, it may be more open to moderation from individual difference variables (Williams, 2007). Thus, moderation was expected to be more pronounced for participants who were partially ostracized than those who were fully ostracized (see Figure 1). 


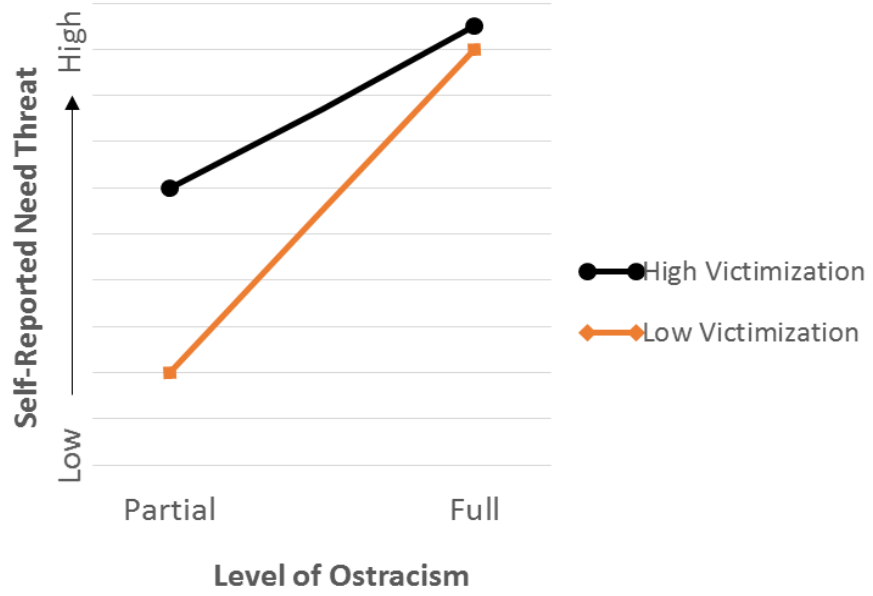

Figure 1. Hypothesized interaction of condition by victimization history related to need threat.

In the present study, participants' history of aggressive behaviors were assessed with a self-report measure of perpetration of physically, verbally, and relationally aggressive behaviors. The role of aggressive behaviors and affective responses to ostracism have not been examined by researchers in the past, but research regarding the psychosocial functioning of bullies may provide insight into these responses. For example, Reinjtjes et al. (2013) found that children who were labeled as bullies by their classmates were also labeled as popular. In addition, bullies perceived themselves as highly socially competent. Thus, children who are bullies may not think that their interactions with others pose a problem for their social standing, especially since bullies often do have friends (Espelage \& Holt, 2001; Salmivalli \& Peets, 2009).

Because children and adolescents who are bullies are likely to have friends, it was anticipated that participants' self-reported engagement in aggressive behaviors would diminish the impact of lab-based ostracism on reported need threat. That is, participants 
reporting more frequent aggressive behaviors would report lower need threat in response to ostracism compared to participants who report less perpetration of aggressive behaviors. As stated in the previous hypothesis, this effect was expected to be more pronounced for participants who were partially ostracized than those who were fully ostracized (see Figure 2).

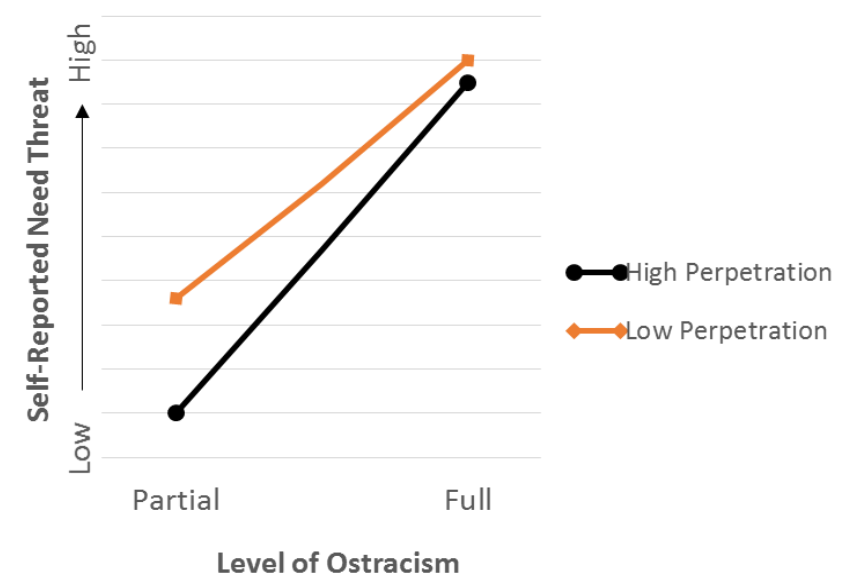

Figure 2. Hypothesized interaction of condition by history of perpetration related to need threat.

\section{Research Question 2A}

Does being fully versus partially ostracized significantly affect participants' behavioral responses (i.e., ingratiating behaviors to players via resource allocations) following the exclusion experience?

\section{Hypothesis 2A: Prosocial, ingratiating behavioral responses to partial versus}

full ostracism. Participants' behavioral responses to ostracism were assessed using a resource allocation activity during which participants decided how many cookies to give to the e-players who ostracized them in the game, a new player who had not yet been 
involved in the game (i.e., did not participate in the ostracism), as well as themselves. Specifically, this study compared the average number of cookies allocated to the two eplayers who ostracized the participant versus the number allocated to a new e-player. According to theories by Williams and Nida (2011) and Smart Richman and Leary (2009), individuals who perceive that reinclusion in the group is possible will behave more prosocially following exclusion, and this will assist in fortifying belonging and self-esteem needs. If reinclusion does not seem possible, however, individuals may be more likely to respond less prosocially in attempts to fortify control or meaningful existence needs. Leja, Wesselmann, and Landau's (2014) pilot study revealed that girls who were asked to allocate cookies after Cyberball ostracism tended to give more cookies to the ostracizing e-players following partial ostracism (compared to girls who were fully ostracized). Therefore, as the partial ostracism condition is designed to simulate an experience in which participants believe they may be able to regain inclusion during the second game of Cyberball, it was expected that participants in this partial ostracism condition would allocate more resources (i.e., cookies) to the ostracizing eplayers (compared to the new player) than participants who were fully ostracized.

In addition, ostracism is known to cause individuals to seek belonging from other groups or individuals (Smart Richman \& Leary, 2009). Indeed, research with adults has shown that individuals who have been rejected give more rewards to new interaction partners who have not yet rejected them, but only when expecting a future interaction (Maner et al., 2007). Further, research with children and adolescents revealed similar results, as girls who were fully ostracized during a game of Cyberball (compared to girls 
who were partially ostracized) tended to give more cookies to the new e-player who had not yet been involved in the game (Leja, Wesselmann, \& Landau, 2014). Thus, when considering participants' cookie distribution to the new e-player, it was anticipated that those who were fully excluded (compared to partially excluded) in the game would allocate more cookies to the new e-player (compared to the old, ostracizing players) who did not ostracize them as a means of seeking alternative affiliation. Leja, Wesselmann, and Landau (2014) also found that girls who were fully ostracized gave themselves more cookies than girls who were partially ostracized. Thus, was also expected that girls who were fully ostracized would give themselves more cookies compared to girls who were partially ostracized.

\section{Research Question 2B}

Do girls' individual differences in history of relational aggression victimization and perpetration moderate the effects of ostracism on participants' attempts to ingratiate after being ostracized in the Cyberball game?

\section{Hypothesis 2B: Moderating effect of self-reported history of victimization}

and perpetration on ingratiation. As described in Hypothesis $1 \mathrm{~B}$, children and adolescents who have a history of physical and relational aggression have reported greater need threat following ostracism than youth who have not been victimized (Ruggieri et al., 2013b). To date, no research has examined the role that victimization history plays on child and teen behavioral responses to ostracism. Bullying research, however, may provide clues as to how children and adolescents will respond. For example, Barker et al. (2008) and Ostrov and Godleski (2013) found that victimization by 
bullies is a significant predictor of future engagement in bullying and relational aggression.

In this study, girls' behavioral responses were expected to follow the same pattern described in Hypothesis 2A that is based on Smart Richman and Leary's (2009) and Williams and Nida's (2011) theories regarding need fortification. Specifically, girls who were partially excluded were expected to give more cookies to ostracizing e-players than girls who were fully excluded, and girls who were fully excluded were expected to give more cookies to the new e-player than girls who were partially excluded. It was anticipated, however, that history of victimization would diminish this effect. Thus, the difference in cookies distributed to the two ostracizing game players (Players 1 and 2) and the new player would be less for those who self-reported greater victimization and who were partially ostracized. That is, participants who had been exposed to more victimization would be less likely to ingratiate themselves to those who partially excluded them than participants who had experienced less victimization in the past. As such, the difference between cookies distributed to the ostracizing players and the new player would be less (i.e., highly victimized participants would not give more cookies to the old players as a means to buy their way back into the game). Because full ostracism through Cyberball is such a powerful manipulation (Williams, 2007), it was not expected that victimization history would moderate fully ostracized participants' response in resource allocation (see Figure 3). 


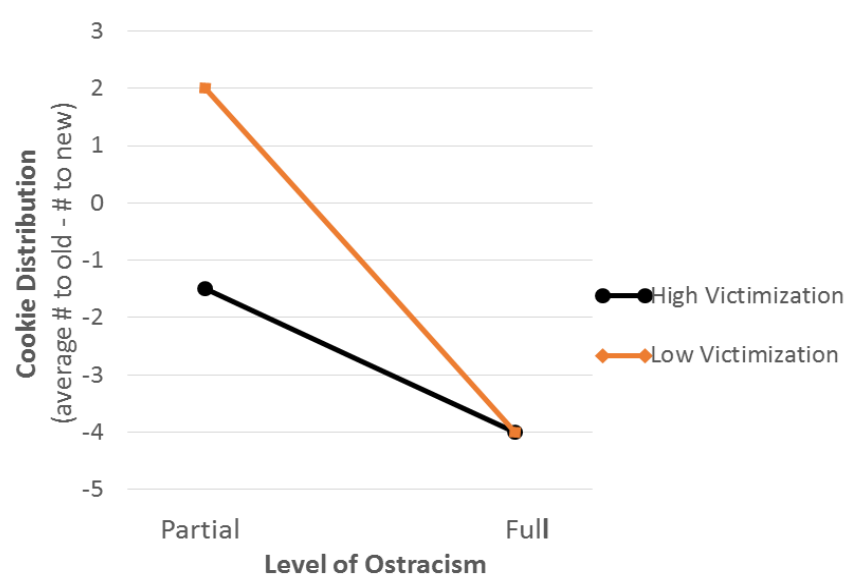

Figure 3. Hypothesized interaction of condition by victimization history related to cookie distribution.

Examination of the relationship between perpetration of aggressive behaviors and ingratiating behavioral responses following ostracism has not been pursued in previous research. In this study, it was expected that self-reported engagement in aggressive behaviors would moderate girls' responses to ostracism experienced during Cyberball. Given bullying research indicating that children who are aggressive and act as bullies are often reactively aggressive (i.e., aggressive in response to provocation or anger; Camodeca et al., 2002; Dodge \& Coie, 1987; Salmivalli \& Nieminen, 2002), it was anticipated that girls who reported more frequent engagement in relational aggression perpetration will be less ingratiating towards the e-players than girls who reported less frequent engagement in relational aggression. As such, the difference between cookies distributed to original players versus the new player would be diminished for the girls who reported more frequent aggressive behaviors. Specifically, after being partially ostracized, girls who self-reported more relational aggression would allocate fewer 
cookies towards ostracizing game players (compared to the new player) than girls who self-reported that they have engaged in few or no relationally aggressive behaviors. As with victimization, perpetration of aggressive behaviors was not expected to moderate responses in the full ostracism condition (see Figure 4).

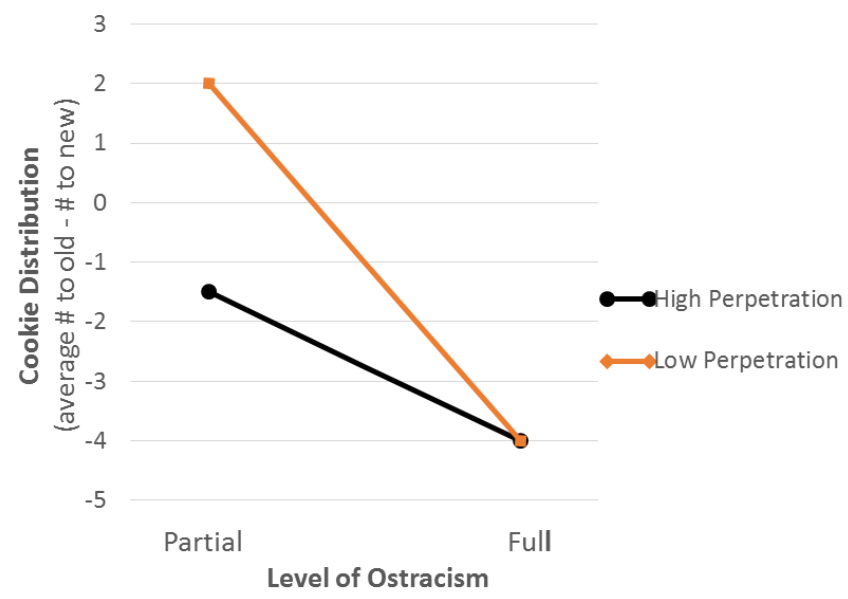

Figure 4. Hypothesized interaction of condition by history of perpetration related to cookie distribution. 


\section{CHAPTER III \\ METHOD \\ Participants}

Participants included 110 middle school-aged girls (grades $5^{\text {th }}$ through $8^{\text {th }}$ ) in general education. A target number of 108 participants had been determined through a power analysis anticipating a medium effect size $\left(f^{2}\right)$ of .15 , power of .90 , and $p=.05$ (Cohen, 1988). This effect size was informed from a pilot study using methodology similar to this study (Leja et al., 2013). Participants were limited to females, as research indicates that relational aggression is more prevalent among females given girls' greater need for intimacy and subsequent greater vulnerability to relational aggression (Archer, 2004; Crick, Casas, \& Mosher, 1997; Crick \& Nelson, 2002; Cullerton-Sen \& Crick, 2005; Rose \& Rudolph, 2006). Further, research has shown that relational aggression is most prevalent during the middle school years (Archer \& Coyne, 2005; Vitaro, Brendgen, \& Barker, 2006). Female students were recruited through letters to parents that were sent home by classroom teachers in three middle schools in central Illinois. All participants received a \$10 Amazon gift card for their participation during Part 2 of the study. In addition, none of the schools were implementing formal bullying prevention programs at the time of data collection.

Descriptive analyses were conducted to examine the sample of participants. Regarding grade in school, $27.3 \%$ were in fifth grade, $27.3 \%$ were in sixth grade, $32.7 \%$ 
were in $7^{\text {th }}$ grade, and $12.7 \%$ were in eighth grade. Ages ranged from 127 months $(10.58$ years) to 175 months (14.58 years) with a mean age of 148.54 months (12.37 years). Students from three schools participated, with $39.1 \%$ of the sample attending School A, 47.3\% attending School B, and 13.6\% attending School C. Based on Illinois Report Card data from 2014-2015 (Illinois State Board of Education, 2016), School A has 485students enrolled in their middle school that serves grades five through eight. The majority of students are White (94\%), and $27.6 \%$ of students are eligible for free or reduced-price lunch. School B is a larger middle school with 895 students enrolled in grades six through eight. School B is also more diverse than School A, with $69.7 \%$ of students identifying as White, $12.4 \%$ as Black, $6.0 \%$ as Asian, $6.9 \%$ as two or more races, $4.6 \%$ as Hispanic, and $0.3 \%$ as American Indian. In addition, $30.8 \%$ of students at School B are eligible for free or reduced-price lunch. Finally, School C is a small elementary school serving 265 children in Kindergarten through fifth grade. 58.5\% of students at School C are White, with $15.1 \%$ identifying as Asian, $14.3 \%$ identifying as Black, $6.8 \%$ as having two or more races, and $0.4 \%$ as American Indian. At School C, $41.9 \%$ of students are eligible for free or reduced-price lunch.

\section{Measures}

\section{Individual Differences in Social-Cognitive Functioning}

Individual differences in girls' social-cognitive functioning that were hypothesized to moderate participants' responses to ostracism were assessed through multiple self-report scales. These measures addressed participants' history of overt and relational victimization and receipt of prosocial acts from peers, personal engagement in 
aggressive and prosocial behaviors, normative beliefs about aggression, and need to belong. All four individual difference measures were administered in a group setting at least one week prior to participants' engagement in the Cyberball game.

Victimization History. Recent research with children has shown that, when compared with a group who are not victimized by their peers, children who are victimized respond differently to single episodes of ostracism (Ruggier et al., 2013a). Specifically, victimized children who were ostracized during Cyberball reported more negative mood and less meaningful existence than non-victimized children who were ostracized. Participants' history of victimization by peers was assessed using the Social Experience Questionnaire (Crick \& Grotpeter, 1996).

The Social Experience Questionnaire (SEQ; Crick \& Grotpeter, 1996) is a 13item self-report measure containing three subscales assessing overt victimization (e.g., “How often do you get hit by another kid at school?"), relational victimization (e.g., "How often has another kid told lies about you to make other kids not like you anymore?"), and receipt of prosocial acts (e.g., "How often does another kid give you help when you need it?’). Participants were asked to report frequency using a 5-point Likert scale ranging from "never" to "all the time," with higher scores indicating greater frequency of experiences with overt victimization, relational victimization, or receipt of prosocial acts (Crick \& Grotpeter, 1996).

Factor analysis of the SEQ (Crick \& Grotpeter, 1996) demonstrated that these subscales represented distinct aspects of peer treatment, with factor loadings for the three scales ranging from .66 to .81 . In addition, intercorrelations between the overt and 
relational victimization factors are low, indicating that these subscales characterize unique victimization experiences (Storch, Crisp, Roberti, Bagner, \& Masia-Warner, 2005). All three subscales are reported as internally consistent, with alpha coefficients of $.77, .78$, and .80 for the prosocial receipt, overt victimization, and relational victimization scales, respectively (Crick \& Grotpeter, 1996). In addition, further research has shown that self-reported victimization using the SEQ significantly correlates with peer reports of the same (Crick \& Bigbee, 1998). SEQ (Crick \& Grotpeter, 1996) internal consistency coefficients were calculated for the current sample and were similar to those reported by the scale authors (see Table 1).

Table 1

Descriptive Statistics for the SEQ $(N=110)$

\begin{tabular}{lccc}
\hline & $\alpha$ & $M$ & $S D$ \\
\hline Relational Victimization & .85 & 11.95 & 3.89 \\
Overt Victimization & .75 & 4.59 & 2.08 \\
Prosocial Receipt & .79 & 19.17 & 3.49 \\
\hline
\end{tabular}

Engagement in Aggressive Behaviors. Participants's self-reported engagement in aggressive behaviors was assessed using the Children's Social Behavior Scale - SelfReport (CSBS-S; Crick \& Grotpeter, 1995). Originally constructed as the Children's Peer Relations Scale (Crick, 1991), the CSBS-S is a 15-item self-report measure that asks participants to report how often they behave in the manner described by the item. The measure includes six subscales assessing how often one engages in relational aggression 
(e.g., "Some kids tell lies about a classmate so that the other kids won't like the classmate anymore.”), physical aggression (e.g., "Some kids hit other kids at school.”), prosocial behavior (e.g., "Some kids try to cheer up other kids who feel upset or sad."), inclusion (e.g., "Some kids have a lot of friends in their class."), verbal aggression (i.e., "Some kids yell at others and call them mean names."), and loneliness (i.e., "Some kids wish that they had more friends at school."). Participants will respond along a 5-point Likert scale ranging from "never" to "all the time," with higher scores representing greater engagement in the behaviors described (Crick \& Grotpeter, 1995).

Psychometric data for this measure have been mixed, as researchers often use specific subscales that fit their research purposes. Crick and Grotpeter (1995), however, found that the subscales were reliable, with alpha coefficients ranging from .66 to .82 . Studies using the relational aggression, overt aggression, and prosocial subscales of the CSBS-S have also shown adequate reliability (Sutch, 2005; Quigly, 2008), as well as the presence of two distinct factors when examining the relational and overt aggression items (Sutch, 2005). For this study, the relational, physical (overt), and prosocial behavior scales of the CSBS-S were chosen for its question format and item content, both of which closely resemble the SEQ (Crick \& Grotpeter, 1996). Internal consistency coefficients for the current sample can be found in Table 2. Further, based on the means of both victimization and perpetration obtained from the current sample, girls participating in this study seemed representative of those described in other reports (e.g., Crick \& Grotpeter, 1996; Storch et al., 2005; Sutch, 2005). 
Table 2

Descriptive Statistics for the CSBS-S $(N=110)$

\begin{tabular}{lccc}
\hline & $\alpha$ & $M$ & $S D$ \\
\hline Relational Aggression & .76 & 7.76 & 2.76 \\
Overt Aggression & .71 & 2.71 & 1.30 \\
Prosocial Behavior & .68 & 16.25 & 2.37 \\
\hline
\end{tabular}

Normative Beliefs About Aggression. Girls' normative beliefs about aggression were measured using the Revised Normative Beliefs about Aggression Scale (NOBAGS; Huesmann \& Guerra, 1997). This 13-item self-report scale assesses individuals' attitudes and tolerance for both overt aggression (e.g., "In general, it is OK to hit other people") and relational aggression (e.g., "If you're angry, it is OK to say mean things about other kids to your friends"). Participants responded using a 4-point Likert scale ranging from "it's really wrong" to "perfectly OK." Higher scores indicated the participant is more likely to approve or tolerate aggression when faced with social problems (Huesmann \& Guerra, 1997). Previous research among middle school-aged children conducted by Martinez-Dick and Landau (2008) indicates high internal consistency for both the overt and relational aggression subscales (i.e., alpha coefficients of .80 and .83, respectively). In addition, scores on the NOBAGS correlate significantly with peer, teacher, and selfreports of aggressive behavior (Huesmann \& Guerra, 1997).

In this study, the NOBAGS was used to offer further descriptive information about individual differences among participants, and was expected to provide concurrent validity with regard to girls' self-report of engagement in aggressive behaviors on the 
CSBS-S (Crick \& Grotpeter, 1995). The internal consistency coefficients for the NOBAGS for the current sample are shown in Table 3.

Table 3

Descriptive Statistics for the NOBAGS $(N=110)$

\begin{tabular}{lccc}
\hline & $\alpha$ & $M$ & $S D$ \\
\hline Total Beliefs & .82 & 18.57 & 4.72 \\
Relational Aggression & .81 & 9.20 & 3.23 \\
Overt Aggression & .74 & 9.37 & 2.30 \\
\hline
\end{tabular}

Need to Belong. Girls' self-reported need to belong was measured using a modified version of the Need to Belong Scale (NTBS) as shown in Leary, Kelly, Cottrell, and Schreindorfer (2013). This 10-item scales assesses the degree to which individuals desire acceptance from others, seek opportunities to be involved with social groups, and react negatively when rejected. Some of the language on the scale was modified to increase understandability for adolescent participants (e.g., "It bothers me a great deal when I am not included in other people's plans" was changed to read, "It bothers me a lot when I am left out of other kids' plans"). When responding, participants indicate the degree to which a given statement is true or represents them using a 5-point Likert scale ranging from "not at all" to "extremely," with higher scores indicating a greater need to belong.

Leary et al. (2013) report that studies using the NTBS have typically found acceptable reliability, with Cronbach's alphas generally exceeding .80 , and that need to 
belong as measured by the scale is related to other scales measuring individuals' desires for affiliation and interaction with others. In the current study, the mean score on the NTBS was 36.19 with a standard deviation of 7.0. There was also acceptable reliability, with a Cronbach's alpha of .80 .

Expectations Questionnaire. Immediately before playing Cyberball and being ostracized, participants reported on their expectations for the game they were about to play. Specifically, girls were asked to report how much they expected to be included in the game (i.e., "Based on how things have gone at school with other girls, I expect that..."). Participants reported if they expected to be included in the game less than the other players, as much as the other players, or more than the other players. This item was included to obtain information about the extent to which girls feel included in social interactions with their peers.

\section{Participants' Responses to Ostracism}

Self-report measures and engagement in ingratiating behaviors (via cookie distribution) were used as dependent variables in this study. Following their experience with ostracism in the first game, participants completed measures assessing their level of need threat, resource allocation behaviors, and expectations for the second game.

Need Threat. As found with adult research on ostracism, research has shown that ostracism affects children's and adolescents' primary needs for belonging, control, selfesteem, and meaningful existence (Abrams et al., 2011; Hawes et al., 2012; Hawes et al., 2013; Ruggieri et al., 2013b; Ruggieri et al., 2013a). In this study, threats to these four needs following the first Cyberball game and ostracism experience were assessed using 
the Primary Needs Questionnaire-Children (PNQ-C; Zadro et al., 2013). The PNQ-C includes two items each to assess needs for belonging (e.g., "I felt unwanted"), control (e.g., "I felt powerful"), self-esteem (e.g., "I felt liked"), and meaningful existence (e.g., "I felt invisible") for a total of eight items. In addition, a manipulation check item (i.e., "I felt ignored") was included. Participants responded to each item using a 5-point Likert scale ranging from "not at all" to "very much so." After correction for reverse-scored items, higher scores indicated more intense need threat.

Zadro et al. (2013) reported internal consistency for this measure, with Cronbach's alphas of $.60, .73, .79, .80$, and .85 for the meaningful existence, control, selfesteem, belonging, and total needs, respectively. Further research with children has also indicated adequate internal consistency for this measure (Hawes et al., 2012; Hawes et al., 2013) that is comparable to the adult version of the scale (Williams et al., 2002). The internal consistency for total need threat for this sample was slightly higher than that reported by Zadro et al. (2013), with an alpha of $.87, M=33.61, S D=7.44$. SpearmanBrown coefficients were calculated for the individual needs, as this statistic has been found to be most appropriate for two-item scales (Eisinga, Grotenhuis, \& Pelzer, 2013). As shown in Table 4, internal consistency coefficients for this sample were slightly higher for meaningful existence and control, and slightly lower for self-esteem and belonging, as compared to Zadro et al. (2013). 
Table 4

Descriptive Statistics for the $P N Q-C(N=110)$

\begin{tabular}{lccc}
\hline & $\rho$ & $M$ & $S D$ \\
\hline Meaningful Existence & .73 & 7.04 & 2.32 \\
Control & .78 & 8.68 & 1.74 \\
Self-Esteem & .76 & 6.94 & 2.18 \\
Belonging & .71 & 7.21 & 2.01 \\
\hline
\end{tabular}

Resource Allocation. Allocation of resources occurs when a designated individual distributes resources (e.g., rewards) to others (Cook \& Hegtevedt, 1983). Within the context of research with children, allocation of resources represents a situational test (i.e., a controlled activity that elicits various prosocial vs. selfish behaviors) through which children's behavior can be assessed. For example, activities in which children receive rewards and are given the opportunity to donate some of them may tap into proclivities for prosocial behavior (Eisenberg \& Mussen, 1989). For the purposes of this study, resource allocation of cookies was used as a behavioral measure of participants' response to ostracism (i.e., their willingness to ingratiate themselves with the e-players following ostracism to increase their chance of being included in the second game).

Participants engaged in this resource allocation activity in which they were asked to distribute 10 cookies between the two ostracizers (original e-players 1 and 2) and a new player who would be included in the next game. Participants were instructed to distribute their cookies any way they wish, but that they must distribute all 10 . Using 10 cookies resulted in a forced choice for the participant, as she needed to decide how to 
reconcile an uneven distribution to the three e-players (two from the first game and one new player). Ingratiating behavior was defined through the patterns in cookie distribution to the e-players. Differences in the average number of cookies distributed to the two ostracizing players and the number allocated to the new player before the second game served as the primary behavioral dependent variable. In addition, participants were asked how much they like cookies (to ensure that they view cookies as a reward), and were given the opportunity to give themselves cookies. Specifically, participants were told that there were another 5 cookies that could be given, and that they could decide how many they wanted to give themselves, the former players, or the new player. This question was used as an additional measure of participants' willingness to ingratiate with the e-players and their willingness to "give up" cookies that could be kept for themselves.

As it was important for the participants to think that the cookies they allocated to each player could affect their level of inclusion during the next game, the researcher informed the participant that the cookies would be given before the second game was played. Further, the researcher left the room for two minutes following this activity, at which time the participant was told "the cookies are being given to the other players."

\section{Expectations Questionnaire (Post Resource Allocation). Participants}

completed a second expectations questionnaire to assess intentions during the resource allocation task. Specifically, participants were asked to think about how much they would be included in the game based on how they decided to distribute the cookies. The response format was the same as the previously completed questionnaire (i.e., choosing if they would be included less than, as much as, or more than other players). Participants 
were asked about their expectations for how much the ostracizing e-players would include them and how much the new e-player would include them. Responses were expected to reflect participants' motives for cookie distribution; for example, giving more cookies to the ostracizing players and expecting greater inclusion would suggest that the participant was trying to ingratiate herself with the ostracizing players.

\section{Procedure}

The lab-based ostracism experience was manipulated using Cyberball (Williams et al., 2000). Cyberball is an online game in which participants toss a ball with other players whom they believe to be real people. These other players, however, were computer programmed to include or ostracize the participant at varying levels (Williams, 2009). Research using Cyberball with children has replicated the typical need threat and lowered mood among adults who experience this type of ostracism (Abrams et al., 2011; Hawes et al., 2012; Hawes et al., 2013; Ruggieri et al., 2013b).

In the current study, participants were told that they are playing Cyberball with two other girls who were participating in another room. As suggested by Zadro et al. (2013), participants were asked to imagine as many details about the game as they could and were told there are no winners or losers. This cover story was meant to relieve performance anxiety or competitiveness that may otherwise have contaminated the ostracism experience. When playing the game, two figures appeared on the participants' computer screen labelled "Player 1" and "Player 2" (on the participants' left and right, respectively), as well as a hand at the bottom of the screen labelled "You." When participants received the ball, they used the computer touchpad to click on the player they 
wished to throw to. Upon completion of the game (i.e., after 30 ball tosses), participants saw a screen thanking them for playing.

In the first Cyberball game with two e-confederates, participants were randomly assigned to experience either partial or full ostracism in which they received either approximately $20 \%$ or $3 \%$ of the ball tosses, respectively. A full inclusion condition (which involves one third of the ball tosses given to the participant) was not used in this study, as pilot study data indicated no differences in resource allocation behaviors when participants were fully included (Leja et al., 2013). Whereas partial ostracism has been relatively under-researched, previous studies show that participants are able to detect this level of ostracism (Banki, 2012; Boyes \& French, 2009; Williams et al., 2000). This was the first known study to examine differences in behavioral responses following these two levels of ostracism.

Participants also played a second game following the resource allocation activity (described above). This game was designed to continue with the cover story that a new player was joining the game, and involved three e-players (i.e., "Player 1" and "Player 2" from the first game, as well as a new figure labelled "New Player"). In this final game, all four participants in the game were equally included (i.e., each receiving $1 / 4$ of the ball tosses). Allowing participants to play a final game in which they were equally included is an important part of the debriefing process to ensure that participants leave the study in a positive state (Hawes et al., 2012; Ruggieri et al., 2013a; Zadro et al., 2013). In addition, each participant left with the number of cookies that she assigned to herself. The procedural sequence is depicted in Figure 5. 


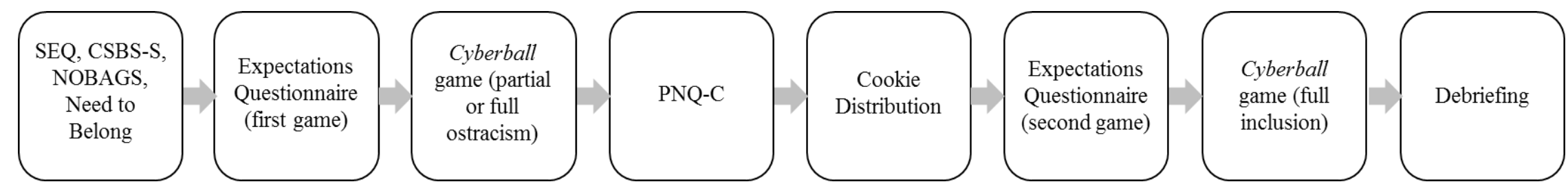

Figure 5. Procedure 


\section{CHAPTER IV}

\section{RESULTS}

\section{Preliminary Analyses}

The current study sought to examine the moderating role of social-cognitive individual differences on middle school-aged girls' responses to ostracism via Cyberball. As part of preliminary analyses, the extent to which data were missing from the selfreported individual difference variables was examined. Missing data for any one participant did not exceed two items, and scores for these items were substituted with the means of completed items. As noted by Pigott (2001), this method is helpful in retaining all participant data but may influence variance.

To determine if there was a developmental effect on participant's responses to ostracism in Cyberball, correlational analyses were conducted to assess the relation between age (in months) and the criterion variables of self-reported need threat, cookie difference scores from each of the two cookie distributions, and number of cookies participants gave to themselves as part of the second distribution. Specifically, difference scores for cookies were calculated by subtracting the mean number of cookies given to Player 1 and Player 2 (the original players) from the number of cookies given to the New Player before the onset of the second game. This difference score was used to examine girls' use of the cookie distribution as an ingratiating behavior and determine to which player(s) girls may try to "buy" inclusion into the second Cyberball game. 
Correlation coefficients indicated that age was unrelated to the cookie difference score between the former players versus the new player from the first distribution, $r=-$ $.04, p=.71$, the cookie difference score from the second distribution, $r=-.08, p=.39$, and the number of cookies participants gave to themselves, $r=-.11, p=.28$. A significant correlation was found between participants' age and self-reported total need threat following the Cyberball game, $r=.27, p<.01$. Given that previous research (e.g., Abrams et al., 2011; Pharo et al., 2011) has found differences in the pattern in which ones' needs can be threatened based on age, additional analyses were conducted to examine the relation between age and the subscales of threats to belonging, self-esteem, control, and meaningful existence. Linear regression analyses indicated that age was a significant predictor of girls' threats to belonging, $b=.05, t_{(1,108)}=3.16, p<.01$, selfesteem, $b=.04, t_{(1,108)}=2.24, p=.03$, and meaningful existence, $b=.04, t_{(1,108)}=2.32, p$ $=.02$. Age did not significantly predict threats to control, $b=.02, t_{(1,108)}=1.22, p=.22$. Thus, as girls' age increased, self-reported threats to belonging, self-esteem, and meaningful existence (but not control) became more pronounced. These results are consistent with previous research examining developmental differences in need threat based on age (Abrams et al., 2011). Because age was a significant correlate of total need threat, it was included as a covariate in subsequent analyses involving need threat. Analyses were also conducted to determine if there was a differential effect of participants' school of attendance as a proxy for school climate differences on selfreported perpetration and victimization of relational and overt aggression. Specifically, four one-way Analyses of Variance (ANOVAs) compared the three schools on 
participants' reported history of perpetration and victimization. Regarding overt aggression, there was no difference among the three schools in terms of either perpetration, $F_{(2,107)}=.55, p=.58, \eta^{2} p=.01$, or victimization, $F_{(2,107)}=.45, p=.64, \eta^{2} p=$ .01 . Also, no difference was found among schools regarding relational victimization, $F_{(2}$, 107) $=.97, p=.38, \eta^{2} p=.02$. However, there was a difference between schools in relational perpetration, $F_{(2,107)}=3.39, p=.04, \eta^{2} p=.06$. Specifically, participants from School B reported greater history of relational perpetration than School A. As such, differences in girls' school was controlled in subsequent analyses involving relational aggression perpetration. An ANOVA was also conducted to determine if differences were found among schools regarding girls' beliefs about the propriety of aggression (i.e., NOBAGS). No differences in aggression beliefs emerged, $F_{(2,107)}=2.04, p=.14, \eta^{2} p=$ .04. Thus, schools were judged to be ostensibly equivalent (with the exception of history of relational aggression perpetration) regarding climate and participants' attitudes pertaining to the use of aggressive behaviors to settle social problems.

Second, to facilitate the interpretation of obtained findings, several Pearson product-moment correlation analyses were conducted to examine the relations between individual difference variables and criterion variables. The following individual difference variables were examined: self-reported relational aggression perpetration and victimization, self-reported overt aggression perpetration and victimization, self-reported engagement in prosocial behavior and receipt of prosocial behavior from others, selfreported beliefs about the propriety of aggression in solving social problems, and selfreported need to belong. Scores for relational perpetration, overt perpetration, and 
engagement in prosocial behavior were obtained from subscales on the $C S B S-S$ (Crick \& Grotpeter, 1995), whereas the relational victimization, overt victimization, and receipt of prosocial behavior scores were obtained from subscales on the $S E Q$ (Crick \& Grotpeter, 1996). One's attitude about the suitability of aggression as measured by the NOBAGS (Huesmann \& Guerra, 1997) were examined as a total score and also as relational and overt aggression attitude subscales. A total need-to-belong score was computed from the NTBS (Leary et al., 2013).

Results of the correlational analyses between predictor variables are displayed in Table 5. Not surprisingly, those reporting a greater history of aggression perpetration (i.e., RePerp and OvPerp) and victimization (i.e., ReVict and OvVict) also reported lower engagement in prosocial behaviors (i.e., PSocB). In addition, girls reporting greater relational, but not overt, aggression histories endorsed more positive attitudes regarding the use of aggression (i.e., Total AB, RelAB, and OvAB). As would be expected, girls reporting greater victimization from aggression indicated less receipt of prosocial behaviors from others (i.e., PSocR) and a greater need to belong and to engage in relationships with others (i.e., NeedB). 
Table 5

Bivariate Correlations between Predictor Variables $(N=110)$

\begin{tabular}{|c|c|c|c|c|c|c|c|c|c|c|}
\hline & 1 & 2 & 3 & 4 & 5 & 6 & 7 & 8 & 9 & 10 \\
\hline \multicolumn{11}{|l|}{ RePerp (1) } \\
\hline ReVict (2) & $.40 * *$ & & & & & & & & & \\
\hline OvPerp (3) & $.46^{* *}$ & $.33^{* *}$ & & & & & & & & \\
\hline OvVict (4) & $.20^{*}$ & $.56^{* *}$ & $.56^{* *}$ & & & & & & & \\
\hline PSocB (5) & $-.32 * *$ & $-.35 * *$ & $-.30 * *$ & $-.30 * *$ & & & & & & \\
\hline PSocR (6) & -.18 & $-.52 * *$ & -.13 & $-.33 * *$ & $.61 * *$ & & & & & \\
\hline TotalAB (7) & $.40 * *$ & $.21 *$ & .05 & .05 & -.03 & -.11 & & & & \\
\hline RelAB (8) & $.35 * *$ & $.19^{*}$ & .00 & .03 & -.02 & -.03 & $.90 * *$ & & & \\
\hline OvAB (9) & $.33^{* *}$ & .15 & .11 & .06 & -.04 & -.18 & $.79 * *$ & $.44 * *$ & & \\
\hline NeedB (10) & .14 & $.32 * *$ & .12 & $.22 *$ & -.06 & .08 & .02 & .08 & -.08 & \\
\hline
\end{tabular}

Note. RePerp = Relational Aggression Perpetration, ReVict = Relational Aggression Victimization, OvPerp = Overt Aggression Perpetration, OvVict $=$ Overt Aggression Victimization, $\mathrm{PSocB}=$ Prosocial Behavior, $\mathrm{PSocR}=$ Prosocial Acts Received, TotalAB $=$ Total Aggression Beliefs, RelAB $=$ Relational Aggression Beliefs, OvAB = Overt Aggression Beliefs, NeedB $=$ Need to Belong.

$* p<.05, * * p<.01$ 
Finally, more frequent perpetration of relational or overt aggression was associated with more victimization from these behaviors. Similar relationships were found for relational perpetration and overt victimization history, as well as overt perpetration and relational victimization history. These results suggest that some participants in this study responded in a way consistent with those of bully-victim status (Ball et al., 2008). As such, an examination of the interaction of perpetration and victimization behaviors was considered in subsequent analyses.

Analyses were also conducted to examine the relations between criterion variables. Girls' reports of greater threat to needs for belonging, self-esteem, control, and meaningful existence following ostracism were associated with more ingratiation with the new player during the first distribution of cookies, $r=.31, p<.01$. Additional analyses also revealed a significant negative Spearman correlation (chosen for its utility in examining correlations involving variables along an ordinal scale; Hauke \& Kossowski, 2011) between participants' ingratiating behavior during the first distribution and their expectations for how Player 1 and Player 2 would treat them during the next game (i.e., whether the original players would include them "less than", "as much as", or "more than the new player"), $r_{s}=-.21, p=.03$. This correlation suggests that participants' intent regarding their inclusion in the next game may be inferred from the manner with which they distributed cookies. Specifically, giving more cookies to the former players relative to the new player was associated with expectations for greater inclusion. Correlational analysis also revealed that the stronger girls' self-reported desire for social relationships, the greater their ingratiation attempt with the new player during the second cookie 
distribution, $r=.23, p=.02$. Girls' need to belong was not related to other criterion variables and was dropped as a potential moderator.

Subsequent analyses focused on the primary hypotheses of the study, including girls' affective and behavioral responses to full versus partial ostracism. During the full ostracism condition, girls received approximately $3 \%$ of all ball tosses, whereas during partial ostracism, girls received approximately $20 \%$ of ball tosses. Thus, while they were included in the game to some extent, girls who were partially ostracized received a share of tosses that was less than probability would predict. In alignment with Williams' (2009) temporal model in which ostracism first affects basic needs for belonging, self-esteem, control, and meaningful existence, variability in girls' affect was examined first. Williams' (2009) model also suggests that individuals' behavioral responses to ostracism are guided by a desire to fortify one's threatened needs. As such, differences in girls' ingratiating behaviors following ostracism were examined second.

\section{Hypothesis Testing}

\section{Research Question 1A}

Does being fully versus partially ostracized have a differential effect on participants' affective responses (i.e., self-reported need threat) following the Cyberball ostracism experience?

This research question was addressed using an Analysis of Covariance (ANCOVA) in which variation in participants' age was controlled due to its significant relation to need threat. It was hypothesized that girls exposed to full ostracism would report greater threats to belonging, self-esteem, control, and meaningful existence than 
those who were partially ostracized. Results indicated this hypothesis was supported, $F_{(1}$, 107) $=10.51, p<.01, \eta_{p}^{2}=.09$, with a medium effect size (Cohen, 1988). Girls who were exposed to full ostracism reported more threatened needs, $M=35.80, S D=7.11$, than girls who were partially ostracized, $M=31.33, S D=7.14$. Thus, girls who were completely excluded from the ball toss game reported that they felt significantly more threatened than those who were only partially left out.

\section{Research Question 1B}

Do individual differences in one's history of relational aggression victimization and/or perpetration moderate the effects of ostracism on participants' resilience to ostracism as defined by need threat?

The Relational Aggression subscale of the SEQ (Crick \& Grotpeter, 1996) was used to examine the effect of relational victimization history on need threat. Specifically, it was hypothesized that a greater history of relational aggression victimization would amplify the effect of ostracism on need threat in the partial ostracism condition compared to the full ostracism condition. Because of the significant correlation between selfreported need threat and age, age was entered in the first step of the regression analysis. In the second step, condition (dummy coded as 0 for full or 1 for partial ostracism) and participants' relational aggression victimization score were entered. Finally, an interaction term representing ostracism condition by one's history of victimization was entered in the third step. Results indicated this hypothesis was not supported, as the effect of ostracism on threat to needs was comparable across girls regardless of their previous 
self-reported victimization, $b=.30, t_{(105)}=.87, p=.39$, indicating that need threat was not influenced by the interaction of ostracism and victimization (see Table 7).

The same analyses were conducted to examine the moderating effect of relational aggression perpetration on the effect of level of ostracism on need threat, with girls' school attended entered at the first step due to its significant relation with perpetration history. In the second step, condition (dummy coded) and participants' relational aggression perpetration score were entered. Then, an interaction term representing ostracism condition by one's history of perpetration was entered in the third step. It was expected that greater perpetration of relational aggression, as measured by the Relational Aggression subscale of the CSBS-S (Crick \& Grotpeter, 1995), would be associated with lower threat to needs following ostracism compared to less frequent perpetration. As with victimization, this hypothesis was not supported, as history of relational perpetration did not change the impact of ostracism condition on girls' reports of need threat, $b=.37, t_{(105)}$ $=.74, p=.46$ (see Table 7). Therefore, the effect of ostracism on girls' threats to belonging, self-esteem, control, and meaningful existence was not influenced by one's history of relational aggression, or the interaction of ostracism and relational aggression.

\section{Research Question 2A}

Does being fully versus partially ostracized significantly affect participants' behavioral responses (i.e., ingratiating behaviors to players via resource allocations) following the ostracism experience?

As previously described, girls' efforts to ingratiate their way back into the game was assessed using a cookie distribution difference score calculated by subtracting the 
mean number of cookies given to Players 1 and 2 (the original ostracizing players) from the number of cookies given to the New Player. Thus, ingratiation to the ostracizing players would be represented by a negative difference score. Drawing from theories suggesting that individuals who more strongly believe reinclusion into a group following ostracism is possible will behave more prosocially or ingratiating towards others than those who are less likely to hold this belief (Smart Richman \& Leary, 2009; Williams \& Nida, 2011), it was anticipated that girls exposed to the partial ostracism condition would distribute more cookies to the original, ostracizing players (compared to the new player) than girls who were fully ostracized, which would produce a negative cookie difference score.

Results indicated a significant differential effect of condition on cookie distribution between full, $M=1.83, S D=2.94$, and partial, $M=.54, S D=2.19$, ostracism; $t_{(102)}=2.60, p=.01, d=.50$ (Levene's test indicated unequal variance, $F=$ 4.43, $p=.04$; so degrees of freedom were adjusted from 108 to 102). Thus, girls who were only partially ostracized made a greater effort to "buy" their inclusion into the next game through the original players than girls who were completely left out. This conclusion pertaining to girls' intent is supported by the significant Spearman correlation indicating that giving more cookies to the old players was associated with a greater expectation of inclusion. This condition effect was not replicated for the second cookie distribution, as there was no difference between the full, $M=.46, S D=.81$, and partial, $M=.31, S D=.83$, ostracism conditions during that distribution; $t_{(108)}=.95, p=.34, d=$ 
.18. As such, the second distribution was dropped from consideration in subsequent analyses.

The number of cookies that girls kept for themselves in the second cookie distribution was also examined to determine if girls exposed to full ostracism would keep more cookies than those only partially left out, possibly as a method of coping with the experience. Results did not reveal a significant effect of condition on cookies distributed to self in the full, $M=1.80, S D=.96$ and partial, $M=1.57, S D=.94$, ostracism conditions; $t_{(108)}=1.26, p=.21, d=.24$.

\section{Research Question 2B}

Do girls' individual differences in history of relational aggression victimization and perpetration moderate the effects of ostracism on participants' attempts to ingratiate after being ostracized in the Cyberball game?

This is the first known study to examine the role that relational victimization and perpetration history play on female teen behavioral responses to ostracism. Consistent with findings for Research Question 2A and in line with Williams' (2009) theory, it was anticipated that girls who were partially ostracized would distribute more cookies to the original ostracizing players than girls who were fully excluded, as the partial ostracism condition simulated an experience where girls believed they could regain inclusion in the next game. However, by extrapolating from bullying research indicating that victimization is a predictor of future engagement in relationally aggressive behaviors (Barker et al., 2008; Ostrov \& Godleski, 2013), it was also hypothesized that one's history of greater victimization would be associated with less ingratiation towards 
ostracizing players. The Relational Aggression subscale of the SEQ (Crick \& Grotpeter, 1996) was examined to determine if ingratiating behavior was differentially affected by victimization history. Ostracism condition (dummy coded) and relational victimization history (i.e., Relational Aggression subscale from the SEQ) were entered separately in the first step of the regression analysis. To test for moderation, the interaction term representing condition by relational victimization history was entered at the second step. Results indicated that this hypothesis was not supported, as the effect of ostracism or its interaction on behavior was comparable across all participating girls regardless of victimization history, $b=.18, t_{(106)}=1.38, p=.17($ see Table 7$)$.

The same analysis was conducted to examine the moderating role of relational perpetration. However, given that relational aggression perpetration differed across girls' schools, the school girls attended (dummy coded) was entered in the first step of the regression analysis. Condition and relational perpetration history, derived from the Relational Aggression subscale of the CSBS-S (Crick \& Grotpeter, 1995), were each entered at the second step of the analysis. Next, the interaction term representing condition by relational perpetration history was entered at the third step as the test of moderation. Moderation was expected to occur following partial ostracism, and it was hypothesized that greater relational perpetration history would be associated with less ingratiation towards the partially ostracizing players. As with victimization, this hypothesis was not supported, $b=.03, t_{(105)}=.14, p=.89$. Together, these moderation analyses indicated that the effect of ostracism on girls' efforts to "buy" their inclusion in 
a second Cyberball game was not qualified by individual differences in history of relational aggression (see Table 7).

\section{Summary of Hypothesis Testing}

Overall, results indicated that girls who were completely left out of a game felt significantly greater threats to belonging, self-esteem, control, and meaningful existence than girls who were only partially excluded. Further, when given the opportunity to "buy" their way into a second game of Cyberball by giving cookies to the original game players, girls who were fully ostracized attempted to secure their inclusion by giving more cookies to a new player who had not been involved in the first game. Compared to those who were completely excluded, girls who were only partially left out by the game players gave more cookies to their ostracizers. None of the individual difference variables, including previous involvement with relational victimization and perpetration, was found to moderate ostracism's effect on girls' affect or behavior.

\section{Additional Findings}

\section{Mediation Involving Need Threat}

As described above, girls' self-reported need threat and ingratiating behaviors differed as a function of exposure to full versus partial ostracism. In addition, there was a significant association found between need threat and girls' behavior in the first cookie distribution, suggesting that girls' threatened needs could explain their use of ingratiating behaviors following ostracism. As such, need threat was examined as a mediator. Mediators are defined as "mechanism(s) through which the focal independent variable is able to influence the dependent variable" (Baron \& Kenny, 1986, p. 1173). This means 
that mediators can be used to explain the process by which one variable is associated with another. In this study, need threat was examined as a potential mechanism for ostracism's influence on girls' ingratiating behavior.

The role of need threat as a mediator was tested using Hayes' (2013) PROCESS macro for SPSS. As such, the current sample of 110 participants was used as a population reservoir from which to draw, with replacement, 1,000 samples of $N=110$. PROCESS (Hayes, 2013) computes unstandardized indirect effects for each bootstrapped sample so the $95 \%$ confidence interval can be determined. The covarying effect of age was controlled in this analysis given its significant relation with need threat. Results revealed that in the first step of the mediation model, the regression of ostracism condition (dummy coded) on the first cookie distribution difference score, ignoring the mediator of need threat, was significant, $b=-1.30, t_{(107)}=-2.60, p=.01$. Step 2 of the analysis indicated that the regression of ostracism condition on the mediator of need threat was also significant, $b=-4.27, t_{(107)}=-3.24, p<.01$. The third step of the mediation process indicated that the mediator (need threat), controlling for condition, was also significant, $b$ $=.11, t_{(106)}=3.04, p<.01$. Finally, Step 4 of the analyses indicated that, after controlling for need threat (the mediator), ostracism condition was no longer a significant predictor of the cookie difference score, $b=-.84, t_{(106)}=-1.67, p=.10$. A Sobel test was conducted and demonstrated full mediation on the model, $\mathrm{z}=-2.17, p=.03$. Thus, ostracism influenced girls' ingratiating behavior because of the need threat that girls experienced following their ostracism. 
In an effort to more precisely determine the mechanism(s) by which ostracism can affect ingratiating behavior, need threat was decomposed into separate needs for belonging, self-esteem, control, and meaningful existence. Table 6 displays the indirect effects of total need threat and each individual need on behavior following ostracism. In addition to the significant effects found for total need threat, both the needs for belonging and meaningful existence emerged as mediators (demonstrated through bootstrapped confidence intervals that are significantly different from zero). However, meaningful existence emerged as a partial mediator, as the effect of ostracism condition on the cookie difference score was lessened, but still significant.

\section{Table 6}

Condition Predicting Cookie Distribution Individual Need Threat Analyses

\begin{tabular}{lcccc}
\hline & Indirect Effect & $\begin{array}{c}\text { Bootstrapped } \\
\text { SE }\end{array}$ & $\begin{array}{c}\text { Bootstrapped } \\
\text { LLCI }\end{array}$ & $\begin{array}{c}\text { Bootstrapped } \\
\text { ULCI }\end{array}$ \\
\hline Total NT & -.46 & .23 & -1.05 & -.12 \\
Belonging & -.48 & .23 & -1.10 & -.16 \\
Self-Esteem & -.24 & .19 & -.77 & .01 \\
Control & -.05 & .07 & -.26 & .05 \\
Meaning Ex & -.28 & .17 & -.72 & -.04 \\
\hline
\end{tabular}

Note. Total NT $=$ Total Need Threat, Belonging $=$ Threat to Belonging, Self-Esteem $=$ Threat to Self-Esteem, Control $=$ Threat to Control, Meaning Ex $=$ Threat to Meaningful Existence

According to Williams' (2009), one's response to ostracism is linked to which specific needs that are threatened, and individuals are likely to respond prosocially to 
address their inclusionary needs (i.e., belonging and self-esteem) or antisocially to fortify needs for power (i.e., control and meaningful existence). Wesselmann, Ren, and Williams (2015) note that this relation between needs and prosocial versus anti-social behaviors is theoretical, but that the limited research that has been conducted has yielded some evidence in support of this theory. As described above, one need from each cluster (i.e., the belonging and meaningful existence needs) mediated ostracism's effect on behavior in this study. Therefore, belonging and meaningful existence were entered into a multiple-mediator model to further investigate the influence of these needs on girls' behavior.

Regarding meaningful existence, the indirect effect was -.15 , and the $95 \%$ confidence interval ranged from -.51 to .07 . Thus, meaningful existence was not significant in this model. The indirect effect for belonging was -.37, with a $95 \%$ confidence interval that ranged from -.90 to -.03 , indicating that the belonging need remained a significant mediator in this model. Overall, these analyses suggest that threatened belonging was the most prominent influence on girls' attempts to "buy" inclusion in a second game of Cyberball following ostracism. Thus, girls' decision regarding to whom they should give their cookies was driven by their attempts to fortify their belonging need, possibly by affiliating with whomever they thought would include them in the next game.

\section{Moderation Involving Overt Victimization and Perpetration}

As described above, neither history of victimization nor perpetration of relational aggression moderated participants' self-reported need threat or differences in ingratiating 
behaviors following ostracism. Of further interest, though, was the moderating role that overt victimization and perpetration played on these two criterion variables. As opposed to relational aggression, history of overt aggression includes involvement with physical forms of aggression (e.g., hitting, pushing).

To determine if history of overt victimization moderated need threat, participants' responses to the Overt Aggression subscale of the SEQ (Crick \& Grotpeter, 1996) were used in regression analyses. Because age and overt victimization were related, $r=-.25, p$ $<.01$, age was entered in the first step of this regression analysis as a covariate. In the second step, condition (i.e., partial vs. full ostracism; dummy coded) and overt victimization history scores were entered. Finally, an interaction term representing condition by overt victimization history was entered in the third step. Results indicated that the effect of ostracism on need threat (affect) was not qualified by its interaction with girls' experience with overt victimization, $b=-.03, t_{(105)}=-.05, p=.96$ (see Table 7). However, analyses involving cookie distribution behavior indicated that overt victimization moderated the effect of ostracism condition on ingratiating behavior, $b=$ $.47, t_{(105)}=2.01, p=.05$, and represented a significant change in explained variance, $\Delta R^{2}$ $=.03, F_{(1,105)}=4.06, p=.05$, with the total model explaining $13 \%$ of the variance in ingratiating behaviors (Table 7). Specifically, for those who were partially excluded from the game, less frequent victimization history was associated with more ingratiation with the ostracizing players (Figure 6). In contrast, greater victimization was associated with greater efforts to "buy" game inclusion through the new player. Girls who were fully ostracized from the game behaved similarly regardless of their victimization histories. 


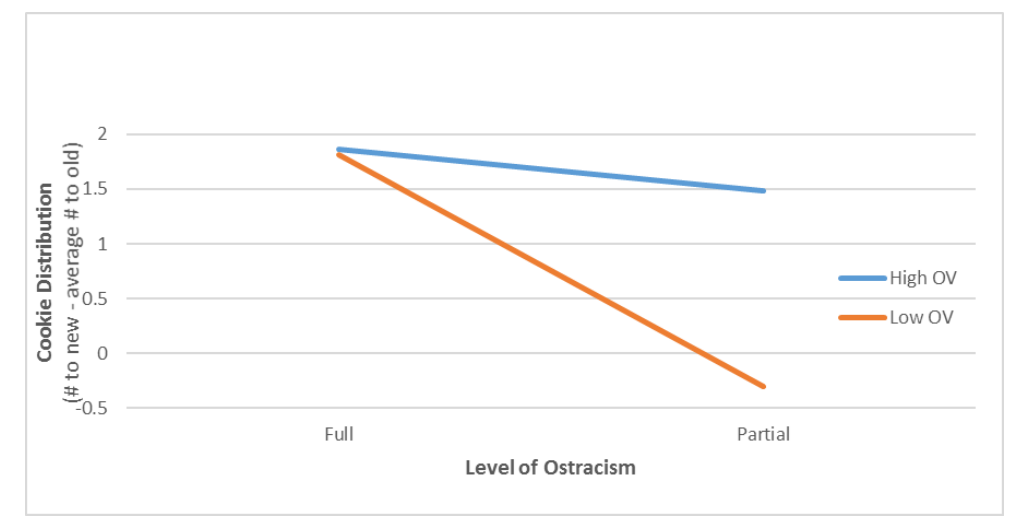

Figure 6. Simple slopes of level of ostracism predicting cookie distribution for $1 S D$ below the mean on overt victimization (i.e., Low OV) and $1 S D$ above the mean on overt victimization (i.e., High OV).

Girls' history of overt perpetration was obtained using the Overt Aggression subscale of the CSBS-S (Crick \& Grotpeter, 1995). The same analysis previously described was conducted to determine the moderating effect of overt perpetration history on need threat and ingratiating behaviors. Overt perpetration did not change the effect of ostracism on need threat, $b=.83, t_{(106)}=.76, p=.45$, or behavior, $b=.57, t_{(106)}=1.46, p$ $=.15$ (Table 7). Thus, only history of overt victimization qualified the effect of partial ostracism on girls" attempts to "buy" inclusion in a second Cyberball game. Specifically, less victimization history was associated with greater effort to gain inclusion by giving more cookies to ostracizing players. In other words, the more likely girls were victimized by overt aggression, the less likely they felt ingratiation with original players would lead to inclusion in the next game. 


\section{Moderation Involving Bully-Victim Status}

As previously described, there were strong, positive associations between participants' histories of perpetration and victimization of both relational and overt aggression. Thus, being a bully puts one at risk for being victimized, and vice versa. As such, girls' combined histories of bully-victim behaviors were examined to determine if bully-victim status moderates the effect of ostracism on affect and behavior.

A variable combining scores from the overt perpetration and victimization subscales (described above) was computed to represent history as bully-victim. Age was entered in the first step of the regression analysis due to its significant association with need threat and overt victimization. In the second step, condition (dummy coded) and the overt bully-victim score were entered separately before the interaction term of condition by bully-victimization was entered in the third step. Although overt bully-victimization did not change ostracism's effect on need threat, $b=.12, t_{(105)}=1.10, p=.29$, it did influence participants' ingratiating behavior following partial ostracism, $b=.09, t_{(105)}=$ 2.42, $p=.02$, and accounted for a significant change in explained variance, $\Delta R^{2}=.05$, $F_{(1,105)}=5.84, p=.02$, with the total model explaining $15 \%$ of the variance in ingratiating behaviors (Table 7). As shown in Figure 7, the more pronounced bully-victim status, the greater was girls' effort to "buy" inclusion from the new player, whereas lower bullyvictimization was associated with greater ingratiation focus on the original ostracizing players. This means that having greater bully-victim status seemed to discourage girls from attempting to gain inclusion in the next game from their ostracizers. History of 
relational bully-victimization did not change ostracism's effect on affect or behavior (see Table 7).

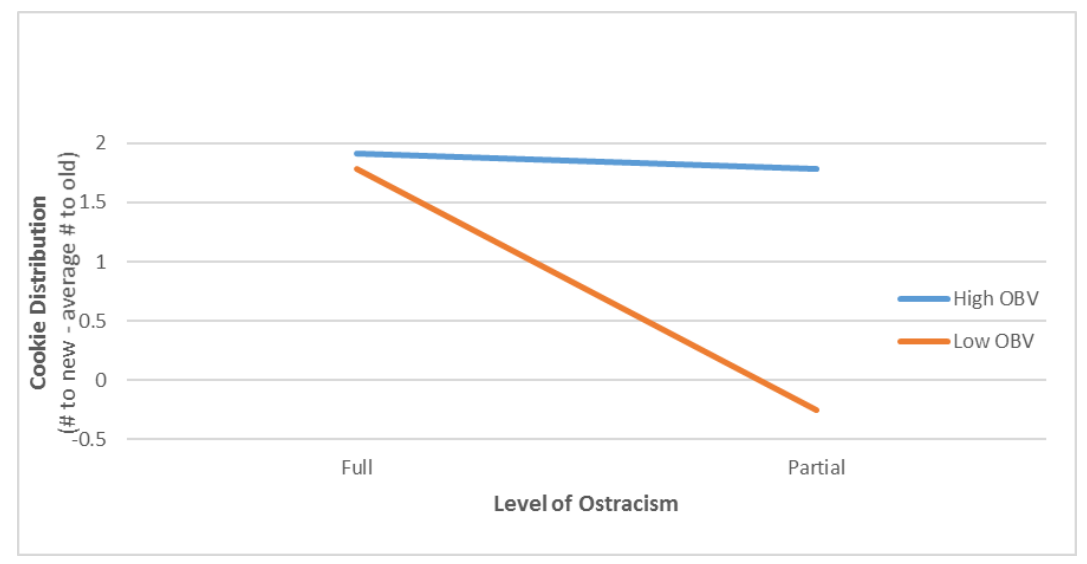

Figure 7. Simple slopes of level of ostracism predicting cookie distribution for $1 S D$ below the mean on overt bully-victim behaviors (i.e., Low OBV) and $1 S D$ above the mean on overt bully-victim behaviors (i.e., High OBV).

Table 7.

Moderation of Victimization, Perpetration, and Bully-Victimization on Need Threat and Ingratiation

\begin{tabular}{|c|c|c|c|c|c|c|c|c|}
\hline \multirow[b]{2}{*}{ Variable } & \multicolumn{4}{|c|}{ Need Threat } & \multicolumn{4}{|c|}{ Ingratiation } \\
\hline & $\beta$ & $t$ & $R^{2}$ & $\Delta R^{2}$ & $\beta$ & $t$ & $R^{2}$ & $\Delta R^{2}$ \\
\hline Con $\mathrm{x}$ RAvict & .377 & .873 & .197 & .006 & .623 & 1.376 & .102 & .016 \\
\hline Con $x$ RAperp & .227 & .746 & .169 & .004 & .044 & .144 & .113 & .000 \\
\hline Con $x$ OAvict & -.012 & -.053 & .227 & .000 & .493 & 2.01 & .127 & $.034 *$ \\
\hline Con x OAperp & .176 & .755 & .103 & .005 & .339 & 1.46 & .108 & .018 \\
\hline Con $x \mathrm{RBV}$ & .206 & .924 & .193 & .007 & .223 & 1.00 & .150 & .008 \\
\hline Con $x \mathrm{OBV}$ & .157 & 1.10 & .202 & .009 & .368 & 2.42 & .147 & $.047 *$ \\
\hline
\end{tabular}

Note: Con = Condition, RAvict $=$ Relational Aggression Victimization, RAperp = Relational Aggression Perpetration, OAvict = Overt Aggression Victimization, OAperp $=$ Overt Aggression Perpetration, RBV $=$ Relational Bully-Victimization, OBV = Overt Bully-Victimization

$* p<.05, * * p<.01$ 
In summary, results indicate the extent to which girls were left out of a ball toss game impacted their feelings of need threat and their attempts to "buy" inclusion in a subsequent game by giving out cookies. Specifically, girls who were completely left out by players in a game of Cyberball experienced greater threats to their needs for belonging, self-esteem, control, and meaningful existence than those who were only partially left out. In addition, girls who were partially ostracized made a greater effort to buy inclusion in the next game through their ostracizers (vs. the new player) than girls who were fully excluded from Cyberball.

One secondary purpose of this study was to determine the moderating role of differences in one's history of relational aggression on need threat and differences in ingratiating behaviors following ostracism. Although one's history of relational aggression as either perpetrator or victim did not qualify the effect of ostracism on need threat or behavior, history of overt aggression did moderate this effect. Specifically, following partial ostracism, a history of less frequent overt victimization or engagement in overt bully-victim behaviors was associated with greater focus on original ostracizing players when giving cookies to ingratiate oneself. However, more frequent victimization or perpetration of bully-victim behaviors were associated with attempts to buy inclusion through the new player who had not been involved in excluding the participant from the previous game. In addition, further examination of the relationship between ostracism and behavior revealed that a threat to belonging was the process that explained how ostracism influenced girls' decision to whom they wanted to ingratiate themselves. It should also be noted that girls' responses on the measures for relational and overt 
perpetration, as well as responses on the measure for overt victimization, were positively skewed. As such, the above analyses were conducted again following a log transformation of data. Using the transformed scores, the pattern of results described above remained unchanged. 


\section{CHAPTER V \\ DISCUSSION}

Social psychologists have long concerned themselves with the study of intergroup relations. The importance of this work is obvious, as humans live and work in a world composed of various groups. As reviewed by Neuberg, Kenrick, and Schaller (2010), group belonging is highly advantageous from an evolutionary standpoint. For example, reproductive fitness, safety, and security are all enhanced by proximity to others and membership in interdependent groups. Group formation does not appear to be entirely random, though, and individuals tend to categorize themselves into groups based on similarities (e.g., race, sex, age) that afford them a social identity (Yzerbyt \& Demoulin, 2010). As described by Yzerbyt and Demoulin (2010), a good deal of research has focused on the conflict that exists between separate groups. Conflict also exists within groups. From an evolutionary standpoint, a group member who was deviant or burdensome could threaten group survival. Although a lack of adherence to social norms is unlikely to be a detriment to a group's physical survival in modern society, individuals still behave in ways to manage deviant behavior of others. As defined by Goffman (1963), a stigma is "an undesired differentness from what we had anticipated" (p. 5); that is, a form of negative deviance from group or individual expectations. Further, Goffman (1963) identified three types of stigmas, including abominations of the body (e.g., physical deformities), tribal stigmas (e.g., race, religion), and flaws in moral character 
(e.g., a criminal history). Avoiding stigma is motivating and has been found to be a primary reason for socially excluding or ostracizing some individuals (Kurzban \& Leary, 2001).

As explained by Thornberg (2011), stigma plays a key role in bullying among youth, with those labelled as deviant often being the targets of this abusive behavior. Unfortunately, bullying is a serious concern among those responsible for protecting today's youth, including parents, educators, and policy-makers. Federally-funded research projects confirm the need for protection, as the National Center for Education Statistics (NCES) reported that $21.5 \%$ of all students aged 12-18 years indicated having been bullied at school in 2013 (Zhang et al., 2016). For years, bullying researchers were concerned with studying overt physical and verbal aggression (Crick \& Grotpeter, 1995; Crick \& Nelson, 2002; Kistner et al., 2010). Behaviors identified in these traditional forms of bullying include hitting, kicking, biting, making threats, and taunting, among others (Ma et al., 2001; Olweus, 1993; Rigby, 2000; Tremblay et al., 2004). Further, a great deal of earlier research implicated males as the likely perpetrators and victims of this form of bullying (Crick \& Nelson, 2002; Kistner et al., 2010). However, a focus on overt forms of aggression does not provide a complete picture of youth bullying phenomena.

Prompted by Crick and Grotpeter's (1995) efforts to more fully understand child and adolescent bullying, researchers began examining relational aggression. Using behaviors such as gossiping, spreading lies, or as discussed above, social exclusion, relational aggression is defined as the removal (or threat of removal) of relationships with 
the intent to harm the victim (Crick \& Grotpeter, 1995; Murray-Close et al., 2007). In contrast to overt aggression, a plethora of more recent research indicates that girls are disproportionally more involved in relational aggression (e.g., Archer, 2004; Crick et al., 1997; Crick \& Grotpeter, 1995; Cullerton-Sen \& Crick, 2005; Ostrov \& Keating, 2004). Indeed, the NCES study lead by Zhang et al. (2015) found that $17.0 \%$ of girls, compared to $9.6 \%$ of boys, had been the subject of hurtful rumors at school. In addition, there is ample evidence that victimization from relational aggression is associated with severe social-psychological problems, such as internalizing and externalizing difficulties, as well as risk for suicidal ideation and suicide attempts (Brunstein Komek et al., 2008; Prinstein et al., 2001; Zwierzynska et al., 2013). A primary strategy and goal of relational aggression includes ostracism, the excluding and ignoring of a victim by others (Williams, 2009).

Ostracism has roots in evolutionary psychology and management of group membership. Specifically, ostracism could be used to strengthen groups by motivating members to adhere to group norms (Wesselmann, Nairne, \& Williams, 2012). Given that those who did not maintain group membership would be susceptible to loss of security and reproductive opportunities offered by the group, detection of the threat of ostracism was highly adaptive (Williams, 2007). Although ostracism from a group is unlikely to lead to death as it may have in aboriginal societies, it does prompt social pain, the negative emotional state that results from exclusion (MacDonald \& Leary, 2005). Indeed, several studies have suggested that ostracism is a source of social pain whose experience may overlap with that of physical pain. For example, Eisenberger et al. (2003) found that, 
in an fMRI scanner, ostracized individuals will show more activation in their dorsal anterior cingulate cortex ( $\mathrm{AACC}$; the regions of the brain associated with processing physical pain) than those who are not ostracized. Given that ostracism from a group is a painful experience, it stands to reason that individuals should try to do whatever they can to join and remain in social groups.

It is easy to see how the importance of group affiliation plays out in adolescent development. Social relationships outside the family become increasingly important during adolescence, as teens begin to rely more on peers for social support and spend more time with others their age (La Greca \& Harrision, 2005; Parker et al., 2006). In addition, social interactions with peers provide opportunities for "social practice" that can assist with developing and maintaining relationships (Juvonen \& Gross, 2005). As such, it is unfortunate the majority of ostracism research pertains to adults. This is especially true given that the limited studies focused on affective or emotional consequences associated with youth ostracism indicate their effects are distinct from other forms of victimization. For example, ostracism appears to differentially influence classroom engagement (Buhs et al., 2006), and has been associated with poorer cognitive performance among school-aged girls (Hawes et al., 2012). Ostracism research has compared children's and adolescents' affective responses to those observed in research with adults, finding this younger population experiences the same threats to needs for belonging, self-esteem, control, and meaningful existence that are consistently found in studies with adults (e.g., Abrams et al., 2011; Ruggieri et al., 2013b). Thus, across all ages, research has confirmed that ostracism hurts. 
The social pain prompted by ostracism has been studied primarily within Williams' (2009) need-threat temporal model of ostracism. Williams (2009) suggests that individuals experience threats to belonging, self-esteem, control, and meaningful existence immediately following ostracism. Further, individuals who have been ostracized will behave in ways to help fortify their threatened needs. While threats to control and meaningful existence may prompt aggressive or anti-social responses, individuals may also emit prosocial responses if their self-esteem or belonging needs have been threated, especially if they believe they can gain inclusion following ostracism (Williams \& Nida, 2011). Since humans are evolutionarily poised to seek group affiliation, behaving in a prosocial manner following ostracism is likely most adaptive.

There is a lack of research examining individuals' behavior following ostracism, and understanding youth behavioral responses to ostracism and how it affects their potential for future social relationships is of critical importance. The consequences of chronic ostracism can be dangerous, as shown by the implication of ostracism history in school shootings (Leary et al., 2003). Thus, the ability of children and teens to establish and maintain successful social relationships with their peers is highly relevant to public health and safety. The few studies examining how children react to ostracism indicate that children may respond antisocially (Coyne et al., 2011) or prosocially (Wölfer \& Scheithauer, 2013) to the experience, as has been suggested in research with adults. However, it is unknown how ostracized children will respond when they are expecting a future interaction with their ostracizers, as they would likely face each day at school. It is also unknown if ostracized youth will make an attempt to ingratiate with ostracizing 
individuals as a means to gain the social inclusion that was taken away, as inclusion is a known crucial facet of teen development. As such, a primary purpose of this study was to examine whether girls would ingratiate with ostracizing others to gain reinclusion in a group.

To this end, participating girls were subjected to two levels of ostracism in a game of Cyberball. Girls were then given the opportunity to ingratiate themselves with game players through engagement in prosocial behavior that involved sharing cookies. Ingratiation was defined in terms of participants' distribution of cookies to ostracizing players versus a new, uninvolved player as a means to gain inclusion in a second game of Cyberball. Of specific interest was girls' preference for influencing a new game player versus individuals who had already excluded them. As described above, Williams and Nida (2011) theorized that individuals with threatened self-esteem or need for belonging, who believe they can gain inclusion following ostracism, will behave prosocially. Results of the current study extend previous ostracism research by testing this theory of need fortification among adolescents who they expect a second interaction with their ostracizers.

\section{Preliminary Findings}

First, participant age was significantly related to level of need threat following ostracism. Specifically, girls' threat to needs for belonging, self-esteem, and meaningful existence become more pronounced with age. Previous studies involving children and adolescents have also found developmental trends in threatened needs (Abrams et al., 
2011). Thus, this study offers further evidence that the social-cognitive responses to ostracism involve developmental phenomena to be studied among teen girls.

Also, interesting findings emerged from correlations involving girls' attitudes about the appropriateness of aggression to solve social problems. Specifically, girls reporting a greater history of involvement with relational victimization or perpetration also reported more acceptance of aggression as a means to solve social problems; however, this association was not found for girls with greater histories of involvement with overt aggression. These findings are not necessarily surprising, though, given previous research indicating that children view behaviors consistent with relational aggression, but not overt aggression, as more normative for girls (Crick et al., 2006), and girls consistently engage in more relational than overt aggressive behaviors (Archer, 2004; Cullterton-Sen \& Crick, 2005).

Another important finding from the preliminary analyses was the association between history of aggression perpetration and victimization, suggesting that greater perpetration was linked to greater victimization (i.e., bully-victim status). This is not surprising, as previous research has identified children who are concurrently involved as bullies and victims as a distinct group. For example, children involved in both bullying and victimization experience unique challenges, including comorbid externalizing and internalizing problems, negative thoughts about themselves and others, and lack of social problem-solving skills (Cook, Williams, Guerra, Kim, \& Sadek, 2010; Marini, Dane, Bosacki, \& YLC-CURA, 2006). Given these unique difficulties, examining associations between bully-victimization and affective responses to ostracism, as well as bully- 
victimization and behavioral responses to ostracism became important in subsequent analyses.

\section{Major Findings}

This study examined effects of ostracism in two domains among teen girls: affective and behavioral. Both domains were studied to extend the literature that has been primarily built upon Williams' (2009) temporal model of ostracism. Specifically, Williams (2009) posited that ostracism first affects individuals' basic needs for belonging, self-esteem, control, and meaningful existence. This is followed by individuals' behavioral responses to ostracism that are directed by the desire to fortify those threatened needs. That is, those who feel threats to self-esteem and belonging should behave prosocially as a way to regain group inclusion, whereas those who feel threats to control and meaningful existence may behave in a way that is antisocial to gain a sense of power over the situation.

This was the first known study to examine how teen girls would behave after they were ostracized, with specific focus on their attempts to gain re-inclusion through "buying their way back in the game" after they had been excluded. This study used resource allocation (i.e., a cookie distribution) to assess ingratiation as a prosocial behavior (Güroğlu, van den Bos, \& Crone, 2014) and to determine with whom girls would most likely seek reinclusion. Prosocial behavior was examined because, as previously discussed, developing and maintaining relationships are highly important for teen social development (Juvonen \& Gross, 2005; Rose \& Rudolph, 2006). 
Results from this study indicated that girls who were fully excluded from the game chose to "buy" inclusion by giving cookies to the new player who had not been involved in their ostracism in the first game. In contrast, girls who were partially left out of the game (compared to those fully excluded) gave significantly more of their cookies to the original ostracizing players. As they previously reported, girls expected that the player(s) to whom they gave cookies would include them in the next Cyberball game. In other words, they thought cookies could be used to "buy" inclusion. These findings extend the research literature in numerous ways. This is the first known study of children and adolescents to examine excluded teens' efforts to ingratiate with their ostracizers as a way to re-gain group inclusion. In addition, given that previous research indicates resource allocation tasks are valid measures of prosocial behavior (Güroğlu et al., 2014), the results of this study offer support for Williams' (2009) theory that individuals will be prosocial toward others to gain inclusion.

As previously discussed, peer relations during the teen years are extremely challenging, and girls' ingratiation in this study sheds light on processes involved in girls' peer relations. Previous research suggests that girls highly value intimacy with peers and will pursue connection-oriented goals, as well as use prosocial strategies to reach those goals and maintain relationships with others (Rose \& Asher, 1999; Rose \& Rudolph, 2006). By informing participants they would play a second game with the same players, girls in this study were led to believe that how they gave out cookies to other players could influence how much the players included them in the next game. This expectation is not unlike girls' peer interactions at school where how the teen responds to being 
ignored by peers is likely to influence how others treat her in the future. The current results suggest that teen girls may use their available resources (in this case, cookies) in ways to increase their chances of group inclusion after they have been ostracized by peers.

As discussed, girls who were partially left out of the game gave more of their cookies to the ostracizing players than did girls who were fully excluded. It is important to note that, overall, girls chose to give more cookies to the new player compared to the ostracizing players. In other words, being partially included in the game did not significantly change girls' desire to attempt to "buy" inclusion from the new player. To extrapolate to girls' peer interactions, these results suggest that girls may need more than just minimal interaction with others to make an effort to maintain those relationships. If that threshold is not reached, girls may invest in developing new relationships with additional peers. Future research could examine at what point girls feel included enough to prefer attempts at maintaining current relationships over seeking new friendships. Such information could be important, as stability in children's friendships is important for future adjustment (including lower levels of aggression and victimization compared to those without stability in friendships; Bowker, Rubin, Burgess, Booth-LaForce, \& RoseKrasnor, 2006).

In addition, girls' attempts to "buy" inclusion in the second Cyberball game was not qualified by their history as a victim or perpetrator of relational aggression. That is, the ostracism experience seemed to be powerful enough to mute any individual differences in relational aggression history. However, girls' ingratiating behavior was 
differentially influenced by individual differences in overt aggression. Specifically, among girls who were partially left out of the game, lower overt victimization and bullyvictimization histories were associated with greater attempts to "buy" inclusion through the initial ostracizing players. Girls who were fully excluded from the game, however, sought inclusion through the new player regardless of relational or overt victimization history.

It is unclear why one's history of overt victimization and bully-victimization, but not relational aggression, influenced girls' ingratiating responses. Comparisons to previous research cannot be made, as this is the first known study to examine in what ways girls' experiences with aggression impact their responses once they have been excluded by others. Indeed, the robust influence of overt aggression history is surprising given that girls are more often involved in relational forms of aggression, whereas boys are more typically involved with overt forms. Because relational aggression perpetration and victimization are more prevalent among teen girls, history of these behaviors may not have been sufficiently substantial to moderate the powerful effect of ostracism. However, it is also possible that relational aggression history did not impact ingratiating behavior because participating girls did not personally know who was ostracizing them. Since ostracism is fundamental to relational aggression, it is possible that the anonymity of the ostracizing players may have attenuated individual differences in ingratiating behavior. Thus, future research should seek to examine whether girls' relational aggression histories differentially affect what they do when they know and do not know the peer who left them out. 
Research conducted by Crick (1997), however, may offer explanation for the significant moderating effect of overt aggression involvement on girls' behavioral response to ostracism. In her study of gender normative versus nonnormative forms of aggression, Crick (1997) discovered that children involved in nonnormative forms of aggression presented with significantly higher levels of psychosocial maladjustment than those involved in gender normative aggression. For example, girls who engaged in overtly aggressive behaviors exhibited significantly greater difficulties (i.e., greater internalizing and externalizing problems, as reported by teachers, as well as self-reports of higher distress and lower self-restraint) than those who engaged in relationally aggressive behaviors. This difference may have been due to greater intolerance of these nonnormative behaviors by peers and adults. In addition, research conducted by Marini et al. (2006) indicated that female bully-victims are temperamentally unique from victims and uninvolved adolescents, as defined by self-reported greater activity levels (e.g., greater endorsement of having a hard time sitting still). Based on these results, Marini et al. (2006) suggested that the aggressive behaviors of these girls may be caused by deficits in self-regulation.

Thus, it seems likely that overtly aggressive girls represent a distinct subgroup of aggressive girls. This may help account for the differential responses to ostracism revealed in this study in which a greater history of overt bully-victimization was associated with lower attempts by girls to "buy" their inclusion through the original ostracizers. For example, if girls who engage in overtly aggressive behaviors do have self-regulation deficits, as Marini et al. (2006) suggest, it is possible that these girls may 
not be sufficiently reflective to choose adaptive, prosocial behaviors to gain reinclusion following ostracism. Current knowledge of bully-victims in general may also support difficulty using adaptive responses to ostracism, as bully-victims have been found to lack social problem-solving skills (Cook et al., 2010). Such claims are limited in this study, however, as girls were forced to give their cookies to either their ostracizers or a new player.

It is also important to note that girls were only given one manner of responding to ostracism in this study - distributing cookies - that was meant to serve as a prosocial act. As previously discussed, research has found that those who are ostracized could respond in different ways, either behaving prosocially or antisocially. Wesselmann, Ren, \& Williams (2015) noted that, when designing studies, researchers tended to focus on one behavioral option for participants. As such, ostracized participants may have responded more extremely than included persons because they have been given only one method to address threatened needs. Thus, to extend the results presented here, future studies should give adolescents the option to either respond aggressively or prosocially towards their ostracizers. Antisocial responding was not assessed in this study, as girls' decisions to give fewer cookies to some players compared to others should not be considered retaliation. For example, participants in future studies could have an opportunity to choose between distributing differing amounts of hot sauce to an individual whom they believe dislikes hot foods as a way to retaliate for being ostracized (see Warburton et al., 2006), or a differing number of cookies to make a prosocial attempt at gaining inclusion, as was the case in this study. 
Further, allowing participants to behave in a way that is either prosocial or aggressive within the same study may help to clarify which type of response may be more prevalent or preferred among ostracized girls, and if responses will truly differ from girls who were included in the game. Research allowing for both responses may also more closely approximate what girls may choose to do when confronted with ostracism from peers at school or in the community. Although prosocial behavior is more adaptive in terms of developing and maintaining relationships (and more closely aligned to girls' relationship values; Rose \& Rudloph, 2006), some girls may not behave prosocially in their daily lives. It is possible that this choice could be influenced by girls' individual differences in relational and overt aggression histories. For example, girls who consider aggression appropriate for handling social problems could more likely behave aggressively after they have been left out. In addition, girls who typically behave aggressively and have been reinforced for this behavior (e.g., by being considered popular, as found by Reijntjes et al., 2013) may also rely on an aggressive response to cope with ostracism (e.g., spreading rumors or gossiping about those who have excluded them). Further, differences in the value placed on close relationships with others could influence girls' choice of aggressive or prosocial responses to ostracism. For example, although girls tend to adopt prosocial, connection-oriented goals, as previously discussed, girls who place a higher value on social status may be more likely to choose an aggressive response to ostracism. Thus, future work in this area is needed to help determine under which circumstances girls may opt for prosocial or aggressive responses to ostracism from peers. 
In addition to being the first known study to examine girls' ingratiating behaviors following ostracism, this study sought to confirm that ostracism affects individuals' basic needs for belonging, self-esteem, control, and meaningful existence among teen girls. Consistent with previous ostracism research with adults (see Williams, 2009) and children and teens (Abrams et al., 2011; Hawes et al., 2012; Pharo et al., 2011; Ruggieri, 2013b), girls in this study who were completely left out of the Cyberball game reported greater feelings of threat to their needs compared to girls who were partially left out of the game. However, there is a lack of studies examining how individual differences among adolescents affect feelings after ostracism. Ruggieri et al. (2013b) presented some evidence that adolescent victimization history moderates need threat following ostracism through Cyberball, with victims of physical and relational aggression reporting lower mood and greater feelings of worthlessness than teens who were not victimized. Unfortunately, Ruggieri et al. (2013b) pooled data across male and female participants. Given known differences in boys' and girls' experiences with physical and relational aggression, pooling these data is methodologically questionable and may leave results uninterpretable.

In contrast to Ruggieri et al. (2013b), the current study only involved girls and was not susceptible to the same concerns with pooled data. Indeed, Ruggieri et al.'s findings are further brought into question given that, in this study, girls' histories with either victimization or perpetration of relational and overt aggression did not influence affective responses to ostracism. This result is consistent with a plethora of previous research indicating that individual characteristics and environmental factors have little to 
no impact on affect after adults have been ostracized (see Williams, 2007, 2009 for a review). Notably, Cyberball studies have shown that individuals feel threats to their basic needs even when they know they have been ostracized by the KKK (Gonsalkorale \& Williams, 2007), when ostracism becomes financially beneficial to them (Van Beest \& Williams, 2006), and when they know their ostracizers are not real, but computer generated people (Zadro et al., 2004). Further, a recent study conducted by Will, van Lier, Crone, and Güroğlu (2016) found that affective responses to ostracism do not differ between adolescents who are socially accepted versus those chronically rejected by peers.

Unfortunately, some girls are exposed to a high rate of relational aggression on a daily basis (Zhang et al., 2015), and ostracism is a key tactic used by relationally aggressive bullies. Thus, the current study provides evidence that ostracism may be so powerful in the moment that individual factors, such as aggression history, may not be sufficiently salient to influence how adolescents feel about being left out. In addition, current findings regarding teen affect offer further evidence that Cyberball is a practical, appropriate method for simulating ostracism with adolescents, given that responses to social ostracism cannot be studied in the naturalistic setting.

Further examination of need threat also revealed the mechanism through which ostracism seems to impact girls' ingratiating behavior. As previously discussed, Williams' (2009) model suggests that individuals respond to ostracism in ways that fortify their threatened needs; thus, ostracism should exacerbate threats to one's basic needs, which in turn drives one's behavior. Several studies have supported this model. For example, fortification of control following ostracism reduces aggression to levels 
comparable to that of included individuals (Warburton et al., 2006). In addition, Bernstein et al. (2010) found that individuals' feelings of threat to belonging and selfesteem following ostracism explained their attempts to affiliate with new people.

In this study, girls' decision regarding how to distribute their cookies seemed to have been driven by an attempt to fortify belonging, as girls were allowed to give cookies to whom they believed would more likely offer reinclusion. Feelings of threat to belonging may be predictive of ingratiation among teen girls. This finding is consistent with Williams' (2009) theory of restoring threatened needs (i.e., to restore their social standing, individuals who feel their social belonging is compromised should be prosocial towards those whom they think will include them). Further, given that girls characteristically place a high value on intimate connection with others and maintaining relationships (Rose \& Rudolph, 2006), it is not surprising that girls in this study felt greater threats to belonging after ostracism, and this prompted their use of a prosocial strategy (i.e., resource allocation) to pursue inclusion.

\section{Summary and Implications}

In summary, the results of the current study offer several important methodological, theoretical, and clinical implications. First, regarding methodological implications, this study provides further evidence that using Cyberball is an appropriate lab-based way to examine adolescent responses to ostracism. Further, this study expands upon research by indicating that a partial ostracism condition is also methodologically desirable for use with teens. Specifically, results indicated that partial ostracism represents a distinct experience from full ostracism, as girls who were fully ostracized by 
game players felt their needs were significantly more threatened than girls who were partially excluded.

Second, regarding the use of behavioral measures, results revealed that the distribution of more cookies to the former ostracizing players relative to the new player was associated with girls' expectations for greater reinclusion. Thus, girls assumed their behavior regarding how to distribute their cookies would be influential in what would occur in the next game. As such, this resource allocation task was shown to be a good representation of ingratiating behaviors that could be used in future laboratory-based studies.

Results from this study also have important theoretical implications. Specifically, results suggest that ostracism has a powerful and harmful effect on girls' affect regardless of individual differences in history. This finding is consistent with Williams' (2009) theory regarding ostracism's impact on needs for belonging, self-esteem, meaningful existence, and control. Specifically, ostracism may have such an immediate and profound impact on one's basic psychological needs that individual characteristics do not matter. Indeed, results in this study are consistent with many studies involving adults (e.g., Gonsalkorale \& Williams, 2007; Van Beest \& Williams, 2006; Zadro et al., 2004) indicating that this ostracism effect resists moderation by individual or situational variables. In addition, the current study adds to Williams' (2009) theory regarding the link between need threat and behavioral responses to ostracism. Girls' attempts to "buy" inclusion in the second game of Cyberball were most strongly influenced by their threatened belonging needs, indicating that girls' attempts to gain inclusion were driven 
by their desire for affiliation with the other players. Previous research has been mixed regarding which needs are most prominent in guiding behavior. However, this study offers support for Williams' (2009) proposition that individuals' prosocial responses are prompted by threats to inclusionary needs.

Current results also have clinical implications for work with middle school-aged girls. Specifically, we know that fully excluded girls' reported higher need threat compared to girls who were partially excluded irrespective of history of aggression involvement. Thus, regardless of girls' experience with relational or overt aggression, either as bully or victim, educators should be aware of the harmful impact ostracism has on one's psychological needs. However, even minimal interaction with others (as simulated in the partial ostracism condition) may be helpful in buffering against the negative feelings associated with ostracism, as suggested by the lower levels of need threat reported by partially ostracized girls. Further, mental health providers working in schools, such as school psychologists and social workers, can and should take steps to help identify those students who are experiencing ostracism. For example, school personnel can use the Bullying and Ostracism Screening Scale (BOSS; Saylor et al., 2012) to assess students' experiences with both bullying and ostracism at the school-wide and individual level. Conducting such screening assessments will help educators better address issues related to their school climate and inform important decisions regarding social-emotional learning curricula as a preventative measure for student problems with bullying or ostracism. 
In addition, because ostracism can be painful for all who experience it, girls should be taught coping strategies to help them manage their feelings of need threat. The use of adaptive coping strategies has been shown to mediate the negative effects of bullying on adolescents (Hampel, Manhal, \& Hayer, 2009), and will likely also help those who are ostracized. Previous research indicates that girls are more likely than boys to seek out social support or use problem-solving approaches (e.g., think of different ways to solve the problem, ask others how they would solve the problem) in response to bullying (Hunter, Boyle, \& Warden, 2004; Skrzypiec, Slee, Murray-Harvey, \& Pereira, 2011). Further, Tenenbaum, Varjas, Meyers, and Parris (2011) found that children perceived the use of problem analysis skills to deliberately think about how to respond to bullying, from whom to seek help, and possible outcomes for various courses of action as more helpful than responding directly to the bully. Although more research may be needed to determine if effective coping strategies differ between victims of more direct forms of bullying and victims of ostracism, the coping literature appears to point to teaching girls problem-solving skills that can be used to cope with their ostracism experience. Given girls' preference for help-seeking when victimized by bullies plus the value girls place on connection with others (Rose \& Rudolph, 2006), teaching girls how to effectively seek out support from adults and uninvolved peers following ostracism may be beneficial, especially if girls are experiencing threats to their need for belonging.

This study confirms the importance girls place on their peer relationships, as results indicate that girls not only believe they can "buy" inclusion from peers, but will attempt this ingratiation when given the means to do so. Attempts to gain inclusion may 
also have important implications for the efforts of school personnel to support healthy relationships. For example, students may benefit from involvement in support groups that allow them to share their experiences with others who have had similar experiences, and these benefits can even be conferred from positive interactions through anonymous online groups (McKenna \& Bargh, 1998). It is possible that structured group interactions may be more beneficial, though, as adults can help monitor those exchanges to help prevent further ostracism from peers that could perpetuate feelings of loneliness and hopelessness. Since girls appear willing to ingratiate with others to gain inclusion, adult guidance and supervision may also be helpful to ensure that girls are not exploited by more socially skilled and powerful peers. Further, given that peer relations offer adolescents opportunities to practice social interactions, some ostracized teens may also need direct instruction in social skills so they can be successful when seeking affiliation with other peers.

In addition, results from this study suggest that a history of relational aggression involvement may not influence girls' behavior following ostracism. However, a history of less overt victimization and overt bully-victimization was associated with greater efforts to gain inclusion through players who had partially excluded participating girls. Although further research is needed to clarify this finding, it seems likely that girls' engaging in overtly aggressive behaviors are qualitatively different than girls who are primarily involved in relationally aggressive behaviors only (as found by Marini et al., 2006). Thus, girls' involved with overt aggression may need interventions that are 
different from those involved with relational aggression, as these girls may be experiencing stronger social sanctions from peers and adults (Crick, 1997).

\section{Limitations}

Several limitations may qualify results of the current study. For example, generalizability is limited to girls in the 5th through 8 th grades and cannot currently be expanded to other populations. In addition, individual difference measures, including histories of involvement with relational and overt aggression, involved self-report and may not reliably represent girls' behavior. Conclusions from this study are also limited to prosocial behaviors through resource allocation activities, and do not inform ingratiating behaviors defined in other ways. As such, conclusions cannot be drawn regarding other prosocial (or antisocial) behaviors that girls may employ when responding to ostracism. Further, sensitive detection of other moderation effects based on relational aggression may have been limited by statistical power.

The environment in which this study was conducted may also limit generalizability. Although girls participated in their schools, Cyberball is an analog for a phenomenon that occurs in the naturalistic setting. Whereas Cyberball is useful in creating the ostracism experience with a high level of experimental control, it does not replicate what adolescents experience in their ongoing relationships with peers. As previously noted, girls in this study were not being excluded by known members of their peer group. Thus, we are unable to assume that this laboratory experience indicates how adolescents would handle ostracism in their daily lives involving those whom they know, and ostracism from unknown individuals may have contributed to the lack of predicted 
moderation of relational aggression history. As noted by Güroğlu et al. (2014), social interactions typically include known individuals, and social behavior is strongly dependent on the relationships that exist with interaction partners. Whereas knowing the ostracizers may have allowed participating girls in this study to reflect upon their relationships with the other players, playing Cyberball with unknown girls did not allow girls to draw upon their unique histories. In addition, this study was predicated on the assumption that aggression history is characterological, which may not be accurate. Thus, relational aggression history may not have been operating as a character trait that would influence responses to ostracism on its own. Instead, typical responses among girls may be situational (e.g., they may have responded differently had they known their ostracizers and drawn upon their relationship history with those individuals, or have responded differently depending on where the ostracism was occurring).

This study relied on resource allocation as a means for assessing girls' attempts to gain inclusion in a Cyberball game by being prosocial towards their ostracizers. As such, participants were given the resources (i.e., cookies) to engage in this ingratiation, with results indicating that girls believe how they allocate their resources will matter for inclusion. However, this study does not inform ostracized girls' behavior when they do not have access to resources that might assist them in gaining group inclusion. Obviously, girls vary in their social skills and knowledge of how to cope with victimization by or ostracism from peers, and some girls may not have the needed skills to effectively manage this situation. Whereas this study assessed girls' attempts to "buy" inclusion 
when the means to do so are equivalent, girls presented with this situation in the naturalistic setting are likely unable to behave in similar ways. 


\section{REFERENCES}

Abrams, D., Weick, M., Thomas, D., Colbe, H., \& Franklin, K. M. (2011). On-line ostracism affects children differently from adolescents and adults. British Journal of Developmental Psychology, 29, 110-123.

Aluede, O., Adeleke, F., Omoike, D., \& Afen-Akpaida, J. (2008). A review of the extent, nature, characteristics and effects of bullying behaviour in schools. Journal of Instructional Psychology, 35, 151-158.

Archer, J. (2004). Sex differences in aggression in real-world settings: A meta-analytic review. Review of General Psychology, 8, 291-322.

Archer, J., \& Coyne, S. M. (2005). An integrated review of indirect, relational, and social aggression. Personality and Social Psychology Review, 9, 212-230.

Ayduk, O., Gyurak, A., \& Luerssen, A. (2007). Individual differences in the rejectionaggression link in the hot sauce paradigm: The case of rejection sensitivity. Journal of Experimental Social Psychology, 44, 775-782.

Ball, H. A., Arseneault, L., Taylor, A., Maughan, B., Caspi, A., \& Moffitt, T. E. (2008). Genetice and environmental influences on victims, bullies and bully-victims in childhood. The Journal of Child Psychology and Psychiatry, 49, 104-112.

Banki, S. (2012). How much or how many? Partial ostracism and its consequences (Doctoral dissertation). Retrieved from University of Toronto: TSpace (http://hdl.handle.net/1807/32659). 
Barker, E. D., Arseneault, L., Brendgen, M., Fontaine, N., \& Maughan, B. (2008). Joint development of bullying and victimization in adolescence: Relations to delinquency and self-harm. Journal of the American Academy of Child \& Adolescent Psychiatry, 47, 1030-1038.

Baron, R. M., \& Kenny, D. A. (1986). The moderator-mediator variable distinction in social psychological research: Conceptual, strategic, and statistical considerations. Journal of Personality and Social Psychology, 51, 1173-1182.

Barry, C. M., \& Wentzel, K. R. (2006). Friend influence on prosocial behavior: The role of motivational factors and friendship characteristics. Developmental Psychology, $42,153-163$.

Baumeister, R. F., \& Leary, M. R. (1995). The need to belong: Desire for interpersonal attachments as a fundamental human motivation. Psychological Bulletin, 117, 497-529.

Berndt, T. J. (2002). Friendship quality and social development. Current Directions in Psychological Science, 11, 7-10.

Berndt, T. J. (2004). Children's friendships: Shifts over a half-century in perspectives on their development and their effects. Merrill-Palmer Quarterly, 50, 206-223.

Bernstein, M. J., Sacco, D. F., Brown, C. M., Young, S. G., \& Claypool, H. M. (2010). A preference for genuine smiles following social exclusion. Journal of Experimental Social Psychology, 46, 196-199.

Bernstein, M. J., Sacco, D. F., Young, S. G., Hugenberg, K., \& Cook, E. (2010). Being "in" with the in-crowd: The effects of social exclusion and inclusion are enhanced 
by the perceived essentialism of ingroups and outgroups. Personality and Social Psychology Bulletin, 36, 999-1009.

Bowker, J. C., \& Etkin, R. G. (2014). Mixed-grade rejections and its association with over aggression, relational aggression, anxious withdrawal, and psychological maladjustment. The Journal of Genetic Psychology, 175, 35-50.

Bowker, J. C., Rubin, K. H., Burgess, K. B., Booth-LaForce, C., \& Rose-Krasnor, L. (2006). Behavioral characteristics associated with stable and fluid best friendship patterns in middle childhood. Merrill-Palmer Quarterly, 52, 671-693.

Boyes, M. E., \& French, D. J. (2009). Having a Cyberball: Using a ball-throwing game as an experimental social stressor to examine the relationship between neuroticism and coping. Personality and Individual Differences, 47, 396-401.

Brunstein Klomek, A., Marrocco, F., Kleinman, M., Schonfeld, I. S., \& Gould, M. S. (2008). Peer victimization, depression, and suicidality in adolescents. Suicide and Life-Threatening Behavior, 38, 166-180.

Bukowski, W. M., Motzoi, C., \& Meyer, F. (2009). Friendship as process, function, and outcome. In K. H. Rubin, W. M. Bukowski, \& B. Laursen (Eds.), Handbook of Peer Interactions, Relationships, and Groups (pp. 217-231). New York, NY: The Guilford Press.

Buhs, E. S., Ladd, G. W., \& Herald, S. L. (2006). Peer exclusion and victimization: Processes that mediate the relation between peer group rejection and children's classroom engagement and achievement? Journal of Educational Psychology, 98, $1-13$. 
Cacioppo, J. T., \& Hawkley, L. C. (2005). People thinking about people: The vicious cycle of being a social outcast in one's own mind. In K. P. Williams, J. P. Forgas, \& W. von Hippel (Eds.), The Social Outcast: Ostracism, Social Exclusion, Rejection, and Bullying (pp. 91-108). New York: Psychology Press.

Camodeca, M., Goossens, F. A., Terwogt, M., \& Schuengel, C. (2002). Bullying and victimization among school-age children: Stability and links to proactive and reactive aggression. Social Development, 11, 332-345.

Card, N. A., Stucky, B. D., Sawalani, G. M., \& Little, T. D. (2008). Direct and indirect aggression during childhood and adolescence: A meta-analytic review of gender differences, intercorrelations, and relations to maladjustment. Child Development, $79,1185-1229$.

Carter-Sowell, A. R., Chen, Z., \& Williams, K. D. (2008). Ostracism increases social susceptibility. Social Influence, 3, 143-153.

Carter-Sowell, A. R., Wesselmann, E. D., Wirth, J. H., Law, A. T., Chen, Z., Kosasih, M. W., .. Williams, K. D. (2010). Strides for belonging trump strides for superiority: Effects of being ostracized for being superior or inferior to others. The Journal of Individual Psychology, 66, 68-92.

Chen, Z., Williams, K. D., Fitness, J., \& Newton, N. C. (2008). When hurt will not heal: Exploring the capacity to relive social and physical pain. Psychological Science, 19, 789-795. 
Cheng, Y., Newman, I. M., Qu, M., Mbulo, L., Chai, Y., Chen, Y., \& Shell, D. F. (2010). Being bullied and psychosocial adjustment among middle school students in China. Journal of School Health, 80, 193-199.

Chow, R. M., Tiedens, L. Z., \& Govan, C. L. (2008). Excluded emotions: The role of anger in antisocial responses to ostracism. Journal of Experimental Social Psychology, 44, 896-903.

Ciarocco, N. J., Sommer, K. L., \& Baumeister, R. F. (2001). Ostracism and ego depletion: The strains of silence. Personality and Social Psychology Bulletin, 27, 1156-1163.

Cohen, J. (1988). Statistical power analysis for the behavioral sciences $\left(2^{\text {nd }} e d.\right)$. Hillsdale, NJ: Erlbaum.

Cook, K. S., \& Hegtvedt, K. A. (1983). Distributive justice, equity, and equality. Annual Review of Sociology, 9, 217-241.

Cook, C. R., Williams, K. R., Guerra, N. G., Kim, T. E., \& Sadek, S. (2010). Predictors of bullying and victimization in childhood and adolescence: A meta-analytic investigation. School Psychology Quarterly, 25, 65-83.

Coyne, S.M., Gundersen, N., Nelson, D. A., \& Stockdale, L. (2011). Adolescents' prosocial responses to ostracism: An experimental study. The Journal of Social Psychology, 151, 657-661.

Craig, W., Harel-Fisch, Y., Fogel-Grinvald, H., Dostaler, S., Hetland, J., Simons-Morton, B., ... Pickett, W. (2009). A cross-national profile of bullying and victimization 
among adolecents in 40 countries. International Journal of Public Health, 54, 216-224.

Crapanzano, A. M., Frick, P. J., \& Terranova, A. M. (2010). Patterns of physical and relational aggression in a school-based sample of boys and girls. Journal of Abnormal Child Psychology, 38, 433-445.

Crick, N. R. (1991, April). Subgroups of neglected and rejected children. Paper presented at the biennial meeting of the Society for Research in Child Development, Seattle.

Crick, N. R. (1995). Relational aggression: The role of intent attributions, feelings of distress, and provocation type. Development and Psychopathology, 7, 313-322.

Crick, N. R. (1996). The role of overt aggression, relational aggression, and prosocial behavior in the prediction of children's future social adjustment. Child Development, 67, 2317-2327.

Crick, N. R. (1997). Engagement in gender normative versus noonnormative forms of aggression: Links to social-psychological adjustment. Developmental Psychology, $33,610-617$.

Crick, N. R., \& Bigbee, M. A. (1998). Relational and overt forms of peer victimization: A multiinformant approach. Journal of Consulting and Clinical Psychology, 66, $337-347$.

Crick, N. R., Bigbee, M. A., \& Howes, C. (1996). Gender differences in children's normative beliefs about aggression: How do I hurt thee? Let me count the ways. Child Development, 67, 1003-1014. 
Crick, N. R., Casas, J. F., \& Ku, H. (1999). Physical and relational peer victimization in preschool. Developmental Psychology, 35, 376-385.

Crick, N. R., Casas, J. F., \& Mosher, M. (1997). Relational and overt aggression in preschool. Developmental Psychology, 33, 579-588.

Crick, N. R., \& Grotpeter, J. (1995). Relational aggression, gender, and socialpsychological adjustment. Child Development, 66, 710-722.

Crick, N. R., \& Grotpeter, J. (1996). Children's treatment by peers: Victims of relational and overt aggression. Development and Psychopathology, 8, 367-380.

Crick, N. R., \& Nelson, D. A. (2002). Relational and physical victimization within friendships: Nobody told me there'd be friends like these. Journal of Abnormal Child Psychology, 30, 599-607.

Cullerton-Sen, C., \& Crick, N. R. (2005). Understanding the effects of physical and relational victimization: The utility of multiple perspectives in predicting socialemotional adjustment. School Psychology Review, 34, 147-160.

Dodge, K. A., \& Coie, J. D. (1987). Social information-processing factors in reactive and proactive aggression in children's playgroups. Journal of Personality and Social Psychology, 53, 1146-1158.

Due, P., Holstein, B. E., Lynch, J., Diderichsen, F., Gabhain, S. N., Scheidt, P., Currie, C. (2005). Bullying and symptoms among school-aged children: International comparative cross sectional study in 28 countries. European Journal of Public Health, 15, 128-132. 
Eisenberger, N. I., Lieberman, M. D., \& Williams, K. D. (2003). Does rejection hurt? An fMRI study of social exclusion. Science, 302, 290-292.

Eisenberg, N., \& Mussen, P. H. (1989). The roots of prosocial behavior in children. New York, NY: Cambridge University Press.

Eisinga, R., Grotenhuis, M., \& Pelzer, B. (2013). The reliability of a two-item scale: Pearson, Cronbach or Spearman-Brown? International Journal of Public Health, $58,637-642$.

Emmons, R. A. (1996). Striving and feeling: Personal goals and subjective well-being. In P. M. Gollwitzer \& J. A. Bargh (Eds.), The psychology of action (pp. 313-337). New York, NY: Guilford Press.

Espelage, D. L., \& Holt, M. K. (2001). Bullying and victimization during early adolescence: Peer influences and psychosocial correlates. Journal of Emotional Abuse, 2, 123-142.

Fleming, L. C., \& Jacobsen, K. H. (2009). Bullying and symptoms of depression in Chilean middle school students. Journal of School Health, 79, 130-137.

Goffman, I. (1963). Stigma: Notes on the management of spoiled identity. Englewood Cliffs, NJ: Prentice Hall.

Gonsalkorale, K., \& Williams, K. D. (2007). The KKK won't let me play: Ostracism even by a despised outgroup hurts. European Journal of Social Psychology, 37, 1176-1186. 
Gross, E. F. (2009). Logging on, bouncing back: An experimental investigation of online communication following social exclusion. Developmental Psychology, 45, 17871793.

Güroğlu, B., van den Bos, W., \& Crone, E. A. (2014). Sharing and giving across adolescence: An experimental study examining the development of prosocial behavior. Frontiers in Psychology, 5, 291.

Hampel, P., Manhal, S., \& Hayer, T. (2009). Direct and relational bullying among children and adolescents: Coping and psychological adjustment. School Psychology International, 30, 474-490.

Hauke, J., \& Kossowski, T. (2011). Comparison of values of pearson's and spearman's correlation coefficients on the same sets of data. Quaestiones Geographicae, 30, $87-93$.

Hawes, D. J., Zadro, L., Fink, E., Richardson, R., O’Moore, K., Griffiths, B., ..., Williams, K. D. (2012). The effects of peer ostracism on children's cognitive processes. European Journal of Developmental Psychology, 9, 599-613.

Hawes, D. J., Zadro, L., Iannuzzelli, R., Godwin, A., MacNevin, G., Dadds, M., ..., Richardson, R. (2013). Internalising problems and the effects of peer ostracism on children's primary needs. International Journal of Developmental Science. Manuscript in press.

Hawker, D. S. J., \& Boulton, M. J. (2001). Subtypes of peer harassment and their correlates: A social dominance perspective. In J. Juvonen \& S. Graham (Eds.), 
Peer harassment in school: The plight of the vulnerable and victimized (pp. 387397). New York, NY: Guilford Press.

Hay, D. F., Payne, A., \& Chadwick, A. (2004). Peer relations in childhood. Journal of Child Psychology and Psychiatry, 45, 84-108.

Holmbeck, G. N. (1997). Toward terminological, conceptual, and statistical clarity in the study of mediators and moderators: Examples from the child-clinical and pediatric psychology literatures. Journal of Consulting and Clinical Psychology, 65, 599610.

Howard, A. M., Landau, S., \& Pryor, J. B. (2014). Peer bystanders to bullying: Who wants to play with the victim? Journal of Abnormal Child Psychology, 42, 265276.

Huesmann, L. R., \& Guerra, N. G. (1997). Children's normative beliefs about aggression and aggressive behavior. Journal of Personality and Social Psychology, 2, 408419.

Hunter, S. C., Boyle, J. M. E., \& Warden, D. (2004). Help seeking amongst child and adolescent victims of peer-aggression and bullying: The influence of school-stage, gender, victimisation, appraisal, and emotion. British Journal of Educational Psychology, 74, 375-390.

Hymel, S., Rubin, K. H., Rowden, L., \& LeMare, L. (1990). Children's peer relationships: Longitudinal predictions of internalizing and externalizing problems from middle to late childhood. Child Development, 61, 2004-2021. 
Illinois State Board of Education (2016). Illinois Report Card 2014-2015 [Data file]. Retrieved from https://www.illinoisreportcard.com/Default.aspx.

Jamieson, J. P., Harkins, S. G., \& Williams, K. D. (2010). Need threat can motivate performance after ostracism. Personality and Social Psychology Bulletin, 36, 690702.

Jones, E. E., Carter-Sowell, A. R., Kelly, J. R., \& Williams, K. D. (2009). “I'm out of the loop": Ostracism through information exclusion. Group Processes \& Intergroup Relations, 12, 157-174.

Juvonen, J., \& Gross, E. F. (2005). The rejected and the bullied: Lessons about social misfits from developmental psychology. In K. D. Williams, J. P. Forgas, \& W. von Hippel (Eds.), The social outcast: Ostracism, social exclusion, rejection, and bullying (pp. 155-170). New York: Psychology Press.

Killen, M., \& Turiel, E. (1998). Adolescents' and young adults' evaluations of helping and sacrificing for others. Journal of Research on Adolescence, 8, 355-375.

Kistner, J., Counts-Allen, C., Dunkel, S., Hardee Drew, C., David-Ferdon, C., \& Lopez, C. (2010). Sex differences in relational and overt aggression in the late elementary school years. Aggressive Behavior, 36, 282-291.

Kuppens, S., Grietens, H., Onghena, P., \& Michiels, D. (2009). Associations between parental controls and children's overt and relational aggression. British Journal of Developmental Psychology, 27, 607-623.

Kurzban, R. \& Leary, M. R. (2001). Evolutionary origins of stigmatization: The functions of social exclusion. Psychological Bulletin, 127, 187-208. 
Ladd, G. W. (1999). Peer relationships and social competence during early and middle childhood. Annual Review of Psychology, 50, 333-359.

La Greca, A. M., \& Harrison, H. M. (2005). Adolescent peer relations, friendships, and romantic relationships: Do they predict social anxiety and depression? Journal of Clinical Child \& Adolescent Psychology, 34, 49-61.

Laird, R. D., Jordan, K. Y., Dodge, K. A., Pettit, G. S., \& Bates, J. E. (2001). Peer rejection in childhood, involvement with antisocial peers in early adolescence, and the development of externalizing behavior problems. Developmental Psychopathology, 13, 337-354.

Lakin, J. L., Chartrand, T. L., \& Arkin, R. M. (2008). I am too just like you: Nonconscious mimicry as an automatic behavioral response to social exclusion. Psychological Science, 19, 816-822.

Leary, M. R., Kelly, K. M., Cottrell, C. A., \& Schreindorfer, L. S. (2013). Construct validity of the need to belong scale: Mapping the nomological network. Journal of Personality Assessment, 95, 610-624.

Leary, M. R., Kowalski, R. M., Smith, L., \& Phillips, S. (2003). Teasing, rejection, and violence: Case studies of the school shootings. Aggressive Behavior, 29, 202-214.

Leja, A. M., Wesselmann, E. D., Landau, S. (2013, February). Girls’ behavioral responses to being left out of a game. Poster presented at the National Association for School Psychologists in Washington, D.C.

Ma, X., Stewin, L. L., \& Mah, D. L. (2001). Bullying in school: nature, effects, and remedies. Research Papers in Education, 16, 247-270. 
MacDonald, G., \& Leary, M. R. (2005). Why does social exclusion hurt? The relationship between social and physical pain. Psychological Bulletin, 131, 202223.

Maner, J. K., DeWall, N., Baumeister, R. F., \& Schaller, M. (2007). Does social exclusion motivate interpersonal reconnection? Resolving the "porcupine problem.” Journal of Personality and Social Psychology, 92, 42-55.

Marini, Z. A., Dane, A. V., Bosacki, S. L., \& YLC-CURA (2006). Direct and indirect bully-victims: Differential psychosocial risk factors associated with adolescents involved in bullying and victimization. Aggressive Behavior, 32, 551-569.

Martinez-Dick, M. K., \& Landau, S. (2008, Feburary). Cyberbullying: Individual differences as predictors of children's harassment of others. Poster presented at the National Association for School Psychologist in New Orleans, LA.

McKenna, K. Y. A., \& Bargh, J. A. (1998). Coming out in the age of the internet: Identity “demarginalization” through virtual group participation. Journal of Personality and Social Psychology, 75, 681-694.

Merrell, K. W., Buchanan, R., \& Tran, O. K. (2006). Relational aggression in children and adolescents: A review with implications for school settings. Psychology in the Schools, 43, 345-360.

Monks, C. P., \& Smith, P. K. (2006). Definitions of bullying: Age differences in understanding of the term, and the role of experience. British Journal of Developmental Psychology, 24, 801-821. 
Murray-Close, D., Crick, N. R., \& Galotti, K. M. (2006). Children's moral reasoning regarding physical and relational aggression. Social Development, 15, 345-372.

Murray-Close, D., Ostrov, J. M., \& Crick, N. R. (2007). A short-term longitudinal study of growth of relational aggression during middle childhood: Associations with gender, friendship intimacy, and internalizing problems. Development and Psychopathology, 19, 187-203.

Neuberg, S. L., Kenrick, D. T., \& Schaller, M. (2010). Evolutionary social psychology. In S. T. Fiske, D. T. Gilbert, \& G. Lindzey (Eds.), The handbook of social psychology (5th ed., Vol. 2, pp. 761-796). Hoboken, NJ: Wiley.

Nezlek, J. B., Wesselmann, E. D., Wheeler, L., \& Williams, K. D. (2012). Ostracism in everyday life. Group Dynamics: Theory, Research, and Practice, 16, 91-104.

O’Connor, L., \& Marans, D. (2016, July 21). Here are 10 examples of Donald Trump being racist. The Huffington Post. Retrieved from http://www.huffingtonpost.com/entry/donald-trump-racistexamples_us_56d47177e4b03260bf777e83

Over, H., \& Carpenter, M. (2009). Priming third-party ostracism increases affiliative imitation in children. Developmental Science, 12, F1-F8.

Olthof, T., \& Goossens, F. A. (2008). Bullying and the need to belong: Early adolescents' bullying-related behavior and the acceptance they desire and receive from particular classmates. Social Development, 17, 24-46.

Olweus, D. (1993). Bullies on the playground: The role of victimization. In C. Hart (Ed.), Children on the playground: Research perspectives and applications (pp. 85- 
128). New York: SUNY Press.

Ostrov, J. M., \& Godleski, S. A. (2013). Relational aggression, victimization, and adjustment during middle childhood. Development and Psychopathology, 25, 801-815.

Ostrov, J. M., \& Keating, C. F. (2004). Gender differences in preschool aggression during free play and structured interactions: An observational study. Social Development, 13, 255-277.

Owusu, A., Hart, P., Oliver, B., \& Kang, M. (2011). The association between bullying and psychological health among senior high school students in Ghana, West Africa. Journal of School Health, 81, 231-238.

Paquette, J. A., \& Underwood, M. K. (1999). Gender differences in young adolescents' experiences of peer victimization: Social and physical aggression. Merrill-Palmer Quarterly, 45, 242-266.

Parker, J. G., Rubin, K. H., Erath, S. A., Wojslawowicz, J. C., \& Buskirk, A. A. (2006). Peer relationships, child development, and adjustment: A developmental psychopathology perspective. In D. Cicchetti \& D. J. Cohen (Eds.), Developmental Psychopathology, Theory and Method (pp. 419-493). Hoboken, NJ: Wiley \& Sons, Inc.

Pharo, H., Gross, J., Richardson, R., \& Hayne, H. (2011). Age-related changes in the effect of ostracism. Social Influence, 6, 22-38.

Pickett, C. L., Gardner, W. L., \& Knowles, M. (2004). Getting a cue: The need to belong and enhanced sensitivity to social cues. Personality and Social Psychology 
Bulletin, 30, 1095-1107.

Pigott, T. D. (2001). A review of methods for missing data. Educational Research and Evaluation, 7, 353-383.

Prinstein, M. J., Boergers, J., \& Vernberg, E. M. (2001). Overt and relational aggression in adolescents: Social-psychological adjustment of aggressors and victims. Journal of Clinical Child Psychology, 30, 479-491.

Quigley, D. (2008). Behind the hurt: Children's underlying emotions and desires and their reported use of relationally as compared to physically aggressive strategies (Unpublished masters thesis). Carleton University, Ottawa.

Reijntjes, A., Vermande, M., Olthof, T., Goossens, F. A., van de Schoot, R., Aleva, L., \& van der Meulen, M. (2013). Costs and benefits of bullying in the context of the peer group: A three wave longitudinal analysis. Journal of Abnormal Child Psychology, 41, 1217-1229.

Rigby, K. (2000). Effects of peer victimization in schools and perceived social support on adolescent well-being. Journal of Adolescence, 23, 57-68.

Rigby, K. (2002). New perspectives on bullying. London \& Philadelphia: Jessica Kingsley.

Rigby, K. (2007). Bullying in schools: and what to do about it. Australia: ACER Press.

Riva, P., Wirth, J. H., \& Williams, K. D. (2011). The consequences of pain: The social and physical pain overlap on psychological responses. European Journal of Social Psychology, 41, 681-687.

Rose, A. J., \& Asher, S. R. (1999). Children's goals and strategies in response to conflict 
within a friendship. Developmental Psychology, 35, 69-79.

Rose, A. J., \& Asher, S. R. (2004). Children's strategies and goals in response to helpgiving and help-seeking tasks within a friendship. Child Development, 75, 749763.

Rose, A. J., \& Rudolph, K. D. (2006). A review of sex differences in peer relationship processes: Potential trade-offs for the emotional and behavioral development of girls and boys. Psychological Bulletin, 132, 98-131.

Ruggieri, S., Bendixen, M., Gabriel, U., \& Alsaker, F. (2013a). Cyberball: The impact of ostracism on early adolescents' well-being. Swiss Journal of Psychology, 72, 103109.

Ruggieri, S., Bendixen, M., Gabriel, U., \& Alsaker, F. (2013b). Do previous victimization experiences accentuate responses to experimentally induced ostracism? International Journal of Developmental Science, 7, 25-32.

Salmivalli, C., \& Nieminen, E. (2002). Proactive and reactive aggression among school bullies, victims, and bully-victims. Aggressive Behavior, 28, 30-44.

Salmivalli, C., \& Peets, K. (2009). Bullies, victims, and bully-victim relationships in middle childhood and early adolescence. In K. H. Rubin, W. M. Bukowski, \& B. Laursen (Eds.), Handbook of peer interaction, relationships, and groups (pp. 322340). New York: Guilford.

Salmivalli, C. \& Voeten, M. (2004). Connections between attitudes, group norms, and behavior in bullying situations. International Journal of Behavioral Development, $28,246-258$. 
Saylor, C. F., Nida, S. A., Williams, K. D., Taylor, L. A., Smyth, W., Twyman, K. A., Macias, M. M., \& Spratt, E. G. (2012). Bullying and Ostracism Screening Scales (BOSS): Development and applications. Children's Health Care, 41, 322-342.

Saylor, C. F., Williams, K. D., Nida, S. A., McKenna, M. E., Twomey, K. E., \& Macias, M. M. (2013). Ostracism in pediatric populations: Review of theory and research. Journal of Developmental Behavioral Pediatrics, 34, 279-287.

Sebastian, C., Viding, E., Williams, K. D., \& Blakemore, S. J. (2010). Social brain development and the affective consequences of ostracism in adolescence. Brain and Cognition, 17, 134-145.

Skrzypiec, G., Slee, P., Murray-Harvey, R., Pereira, B. (2011). School bullying by one or more ways: Does it matter and how do students cope? School Psychology International, 32, 288-311.

Smart Richman, L., \& Leary, M. R. (2009). Reactions to discrimination, stigmatization, ostracism, and other forms of interpersonal rejection: A multimotive model. Psychological Review, 116, 365-383.

Smith, A., \& Williams, K. D. (2004). R u there? Ostracism by cell phone text messages. Group Dynamics: Theory, Research, and Practice, 8, 291-301.

Smith, P. K., Cowie, H., Olafsson, R. F., \& Liefooghe, A. P. D. (2002). Definitions of bullying: A comparison of terms used, and age and gender differences, in a fourteen-country international comparison. Child Development, 73, 1119-1133.

Sommer, K. L., Williams, K. D., Ciarocco, N. J., \& Baumeister, R. F. (2001). When silence speaks louder than words: Explorations into the intrapsychic and 
interpersonal consequences of social ostracism. Basic and Applied Social Psychology, 23, 225-243.

Storch, E. A., Crisp, H., Roberti, J. W., Bagner, D. M., \& Masia-Warner, C. (2005). Psychometric evaluation of the social experience questionnaire in adolescents: Descriptive data, reliability, and factorial validity. Child Psychiatry and Human Development, 36, 167-176.

Sutch, Z. B. (2005). Relational aggression among girls and boys with emotional/behavioral disorders in a special school setting (Doctoral dissertation). Retrieved from the Digital Repository at the University of Maryland (http://hdl.handle.net/1903/3186).

Tedeschi, J. T. (2001). Social power, influence, and aggression. In J. P. Forgas \& K. D. Williams (Eds.), Social influence: Direct and indirect processes, (pp. 109-128). New York: Psychology Press.

Tenenbaum, L. S., Varjas, K., Meyers, J., \& Parris, L. (2011). Coping strategies and perceived effectiveness in fourth through eighth grade victims of bullying. School Psychology International, 32, 263-287.

Thornberg, R. (2011). She's weird! - The social construction of bullying in school: A review of qualitative research. Children and Society, 25, 258-267.

Tremblay, R. E., Nagin, D. S., Séguin, J. R., Zoccolillo, M., Zelazo, P. D., Boivin, M., ... Japel, C. (2004). Physical aggression during early childhood: Trajectories and predictors. Pediatrics, 114, e43-e50. 
Twenge, J. M., Baumeister, R. F., DeWall, C. N., Ciarocco, N. J., \& Bartels, J. M. (2007). Social exclusion decreases prosocial behavior. Journal of Personality and Social Psychology, 92, 56-66.

Twyman, K. A., Saylor, C. F., Saia, D., Macias, M. M., Taylor, L. A., \& Spratt, E. (2010). Bullying and ostracism experiences in children with special health care needs. Journal of Developmental \& Behavioral Pediatrics, 31, 1-8.

Van Beest, I., \& Williams, K. D. (2006). When inclusion costs and ostracism pays, ostracism still hurts. Journal of Personality and Social Psychology, 91, 918-928.

Van Beest, I., Williams, K. D., \& Van Dijk, E. (2011). Cyberbomb: Effects of being ostracized from a death game. Group Processes \& Intergroup Relations, 14, 581596.

van der Wal, M. F., de Wit, C. A. M., \& Hirasing, R. A. (2003). Psychosocial health among young victims and offenders of direct and indirect bullying. Pediatrics, $111,1312-1317$.

Vitaro, F., Brendgen, M., \& Barker, E. D. (2006). Subtypes of aggressive behaviors: A developmental perspective. International Journal of Behavioral Development, 30, 12-19.

Waitt, C. (Producer), \& Hirsch, L. (Director). (2011). Bully [Motion Picture]. United States: The Weinstein Company.

Warburton, W. A., Williams, K. D., \& Cairns, D. R. (2006). When ostracism leads to aggression: The moderating effects of control deprivation. Journal of Experimental Social Psychology, 42, 213-220. 
Wentzel, K. R. (2014). Prosocial behavior and peer relations in adolescence. In L. M. Padilla-Walker \& G. Carlo (Eds.), Prosocial Development: A Multidimensional Approach (pp. 178-200). New York: Oxford University Press.

Wentzel, K. R., Barry, C. M. N., \& Caldwell, K. A. (2004). Friendships in middle school: Influences on motivation and school adjustment. Journal of Educational Psychology, 96, 195-203.

Werner, N. E., \& Hill, L. G. (2010). Individual and peer group normative beliefs about relational aggression. Child Development, 81, 826-836.

Wesselmann, E. D., Butler, F. A., Williams, K. D., \& Pickett, C. L. (2010). Adding injury to insult: Unexpected rejection leads to more aggressive responses. Aggressive Behavior, 36, 232-237.

Wesselmann, E. D., Nairne, J. S., \& Williams, K. D. (2012). An evolutionary social psychological approach to studying the effects of ostracism. Journal of Social, Evolutionary, and Cultural Psychology, 6, 309-328.

Wesselmann, E. D, Ren, D., \& Williams, K. D. (2015). Motivations for responses to ostracism. Frontiers in Psychology, 6, 1-5.

Will, G., van Lier, P. A. C., Crone, E. A., \& Güroğlu, B. (2016). Chronic childhood peer rejection is associated with heightened neural responses to social exclusion during adolescence. Journal of Abnormal Child Psychology, 44, 43-55.

Williams, K. D. (2007). Ostracism. Annual Review of Psychology, 58, 425-452. 
Williams, K. D. (2009). Ostracism: Effects of being excluded and ignored. In M. P. Zanna (Ed.), Advances in experimental social psychology (Vol. 41, pp. 275-314). New York: Academic Press.

Williams, K. D., Bernieri, F. J., Faulkner, S. L., Gada-Jain, N., \& Grahe, J. (2000). The scarlet letter study: Five days of social ostracism. Journal of Personal and Interpersonal Loss, 5, 19-63.

Williams, K. D., Cheung, C. K. T., \& Choi, W. (2000). Cyberostracism: Effects of being ignored over the internet. Journal of Personality and Social Psychology, 79, 748762.

Williams, K. D., \& Gerber, J. (2005). Ostracism: The making of the ignored and excluded mind. Interaction Studies, 6, 359-374.

Williams, K. D., Govan, C. L., Croker, V., Tynan, D., Cruickshank, M., \& Lam, A. (2002). Investigations into differences between social- and cyberostracism. Group Dynamics: Theory, Research, and Practice, 6, 65-77.

Williams, K. D., \& Nida, S. A. (2011). Ostracism: Consequences and Coping. Current Directions in Psychological Science, 20, 71-75.

Williams, K. D., \& Sommer, K. L. (1997). Social ostracism by one’s coworkers: Does rejection lead to loafing or compensation? Personality and Social Psychology Bulletin, 23, 693-706.

Wölfer, R. \& Scheithauer, H. (2013). Ostracism in childhood and adolescent: Emotional, cognitive, and behavioral effects of social exclusion. Social Influence, 8, 217-236. 
Wolke, D., \& Samara, M. M. (2004). Bullied by siblings: Association with peer victimization and behaviour problems in Israeli lower secondary school children. Journal of Child Psychology and Psychiatry, 45, 1015-1029.

Yzerbyt, V., \& Demoulin, S. (2010). Intergroup relations. In S. T. Fiske, D. T. Gilbert, \& G. Lindzey (Eds.), The handbook of social psychology (5th ed., Vol. 1, pp. 10241083). Hoboken, NJ: Wiley.

Zadro, L, Boland, C., \& Richardson, R. (2006). How long does it last? The persistence of the effects of ostracism on the socially anxious. Journal of Experimental Social Psychology, 42, 692-697.

Zadro, L., Hawes, D. J., Iannuzzelli, R. E., Godwin, A., MacNevin, A., Griffiths, B., \& Gonsalkorale, K. (2013). Ostracism and children: A guide to effectively using the cyberball paradigm with a child sample. International Journal of Developmental Science, 7, 7-11.

Zadro, L., Williams, K. D., \& Richardson, R. (2004). How low can you go? Ostracism by a computer is sufficient to lower self-reported levels of belonging, control, selfesteem, and meaningful existence. Journal of Experimental Social Psychology, $40,560-567$.

Zadro, L., Williams, K. D., \& Richardson, R. (2005). Riding to “O” train: Comparing the effects of ostracism and verbal dispute on targets and sources. Group Processes \& Intergroup Relations, 8, 125-143.

Zhang, A., Musu-Gillette, L., \& Oudekerk, B.A. (2016). Indicators of School Crime and Safety: 2015 (NCES 2016-079/NCJ 249758). National Center for Education 
Statistics, U.S. Department of Education, and Bureau of Justice Statistics, Office of Justice Programs, U.S. Department of Justice. Washington, DC.

Zwierzynska, K., Wolke, D., \& Lereya, T. S. (2013). Peer victimization in childhood and internalizing problems in adolescence: A prospective longitudinal study. Journal of Abnormal Child Psychology, 41, 309-323. 